\title{
Like It or Not: When Corporate Social Responsibility Does Not Attract Potential Applicants
}

\author{
Eva Alexandra Jakob ${ }^{1}\left[\right.$ [ $\cdot$ Holger Steinmetz ${ }^{2}\left(\mathbb{D} \cdot\right.$ Marius Claus Wehner $^{3} \cdot$ Christina Engelhardt $^{4} \cdot$ Rüdiger Kabst $^{5}(\mathbb{C}$
}

Received: 2 March 2020 / Accepted: 2 February 2021 / Published online: 30 November 2021

(c) The Author(s) 2021

\begin{abstract}
Companies increasingly recognize the importance of communicating corporate social responsibility (CSR) including their engagement toward employees, the community, the environment and other stakeholder groups to attract applicants. The positive findings on the effect of CSR on applicants' reactions are commonly based on the assumption that companies send a clear signal about their commitment to CSR. However, communication is always contextualized and has become more ambiguous through the increased availability of information online. External stakeholders including actual and potential applicants are confronted with inconsistencies between the way companies communicate CSR activities and their overall CSR performance. Drawing on signaling theory, this article raises the question of how the interaction between strong CSR communication and low CSR performance influences organizational attractiveness. We propose that low CSR performance dampens the effect of CSR communication on organizational attractiveness. Hence, the inconsistency between CSR communication and CSR performance decreases organizational attractiveness. To test our hypotheses, we scraped 67,189 posts published on corporate Facebook career pages by 58 Fortune 500 companies from the time they began their respective career page until June 2018. Surprisingly, our results show that a low CSR performance strengthens the effect of CSR communication on organizational attractiveness. Thus, inconsistencies between CSR communication and CSR performance seem to lead to positive evaluations among applicants.
\end{abstract}

Keywords Corporate social responsibility $\cdot$ Potential applicants $\cdot$ Organizational attractiveness $\cdot$ Corporate social responsibility performance $\cdot$ Signaling theory $\cdot$ Inconsistency $\cdot$ Social media

Eva Alexandra Jakob

eva.jakob@uni-bayreuth.de

Holger Steinmetz

hs@leibniz-psychology.org

Marius Claus Wehner

marius.wehner@hhu.de

Christina Engelhardt

christina.engelhardt@uni-goettingen.de

Rüdiger Kabst

kabst@uni-paderborn.de

1 University of Bayreuth, Universitätsstraße 30, 95447 Bayreuth, Germany

2 Leibniz Institute for Psychology, Universitätsring 15, 54296 Trier, Germany

3 Heinrich-Heine-Universität Düsseldorf, Universitätsstraße 1, 40225 Düsseldorf, Germany

4 Georg-August-Universität Göttingen, Wilhelmsplatz 1, 37073 Göttingen, Germany

5 Paderborn University, Warburger Str. 100, 33098 Paderborn, Germany

\section{Introduction}

Corporate social responsibility (CSR) has intrigued scholars for decades (Aguinis \& Glavas, 2012; Vishwanathan et al., 2020). As such, communicating CSR in terms of companies' support for the community, the environment, and their employees has grown into a strategic function to gain a competitive advantage because CSR helps companies to establish a positive relationship with crucial stakeholders such as applicants (Crane \& Glozer, 2016; Du et al., 2010). Following signaling theory, studies have shown that communicating CSR influences applicants' attitudes toward the company positively, which increases organizational attractiveness (e.g., Albinger \& Freeman, 2000; Tsai et al., 2014; Turban \& Greening, 1996). Scholars have maintained that CSR communication helps by sending signals about the company's role as a responsible employer who cares not only for the stakeholders of the company including employees, but also for the community at large and the environment 
(Newman et al., 2015; Tymon et al., 2010). CSR communication increases organizational attractiveness as applicants anticipate future pride in the company, an alignment of values with those of the employer, and a caring climate of the company (Jones et al., 2014; Kim \& Park, 2011).

However, CSR communication may not always result in positive reactions among stakeholders (Sen et al., 2006; Wagner et al., 2009; Willness, 2019). Recent research shows that CSR communication can produce adverse reactions among customers and employees. Reasons for the negative effect of CSR communication are the attributed motive for the company's CSR engagement (Donia et al., 2019; Ellen et al., 2006), inconsistencies between internal and external CSR efforts (Scheidler et al., 2019), or disparities between a company's former CSR reputation and an upcoming CSR crisis (Gistri et al., 2019). Although studies have described potential boundary conditions of the positive effect of CSR communication on customers' and employees' attitudes and behaviors, discussions of adverse effects of CSR communication on potential applicants remain limited (e.g., Jones et al., 2016; Klimkiewicz \& Oltra, 2017; Rupp et al., 2013). This is surprising considering that applicants are an increasingly critical resource, and the research strand on applicants' reactions to CSR has proliferated since the end of the 1990s (Jones et al., 2014; Tsai et al., 2014; Turban \& Greening, 1996). Therefore, in this paper, we ask how potential applicants react to inconsistencies between CSR communication and overall CSR performance.

Drawing on signaling theory (Rynes, 1991; Spence, 1978), we argue that the effect of CSR communication on potential applicants' reactions and organizational attractiveness depends on companies' overall CSR performance. Communicating CSR displays a company's organizational values, beliefs, and practices toward its stakeholders (Greening \& Turban, 2000; Jones \& Murrell, 2001) because it implies how a company relates to employees, customers, the community, the natural environment, and competitors (Carroll, 1999). However, these signals may be inconsistent with a company's overall CSR performance, that is, "the principles, practices, and outcomes of businesses' relationships with people, organizations, institutions, communities, societies, and the earth, in terms of the deliberate actions of businesses toward these stakeholders as well as the unintended externalities of business activity" (Wood, 2016). For instance, a company might trumpet specific CSR activities (e.g., in raising the company's standards for selecting fair suppliers), yet its overall level of CSR performance is (still) poor (Gistri et al., 2019). Inconsistencies might result from 'greenwashing' that is, deliberately communicating social or environmental practices that do not reflect the actual level of CSR performance (Lyon \& Maxwell, 2011; Wu et al., 2020). Yet, inconsistencies could also occur if companies are transitioning from a lower to a higher level of CSR performance and communicating CSR practices along that way (Schultz et al., 2013). In this case, strong CSR communication might not yet fit the overall level of the CSR performance. Following research on customers and employees on the negative effect of inconsistencies, we propose that the relationship between CSR communication and positive reactions among applicants and organizational attractiveness will decrease the lower the overall CSR performance.

The present study is based on 67,189 posts from 58 Fortune 500 companies on Facebook career pages to investigate the effect of CSR communication on observers' reactions to these messages (i.e., number of likes, number of shares, and affective reactions). Facebook career pages provide the possibility to examine reactions by potential applicants as companies use their media platforms (e.g., Facebook, Instagram) to inform and influence applicants' attitudes in a very early phase of the recruitment process (Allen et al., 2007; Baum \& Kabst, 2014). Additionally, Facebook builds a realworld context to examine reactions to corporate communication, including CSR communication (She \& Michelon, 2019). Social media provides a suitable research environment because it increases the availability of information, provides greater opportunities for interactive communication, and accelerates communication which facilitates reactions to CSR-related content (Etter et al., 2019; Lyon \& Montgomery, 2013).

Our study extends prior findings on the boundary conditions for communicating CSR and the signaling process between potential employers and applicants in three ways. First, our study contributes to the great body of research that investigates the relationship of CSR and applicants' attitudes and behaviors (e.g., Albinger \& Freeman, 2000; Kim \& Park, 2011; Zhang \& Gowan, 2012). By analyzing the boundary effect of CSR performance on applicants' reactions, the present study highlights a crucial tenet of signaling theory, namely that the effectiveness of signaling strongly depends on the consistency of the signal (Celani \& Singh, 2011; Connelly et al., 2010). Although literature on the effect of CSR communication on employees and customers increasingly recognizes the importance of inconsistencies (e.g., De Roeck et al., 2016; Kim \& Choi, 2018; Lee et al., 2019), the role of inconsistencies has gained only limited attention in the vast research body focusing on applicants' reactions to CSR (Connelly et al., 2010; Jones et al., 2019; Willness, 2019).

Second, the present article contributes to the literature of CSR communication and the general CSR literature by highlighting that a holistic view of CSR communication and CSR performance provides a new perspective on the effects of the CSR-signaling process. While inconsistencies in the signaling process have been shown to have negative effects (e.g., De Roeck et al., 2016; Kim \& Choi, 2018; Scheidler et al., 2019), our findings 
surprisingly point to the positive side of inconsistencies. This study's results indicate-contrary to our hypotheses-that the lower the CSR performance, the greater the positive effect of CSR communication on observers' reactions and organizational attractiveness. By integrating CSR communication and CSR performance, which are viewed as enablers of organizational attractiveness, this study shows that their interactive effect has negative consequences on observers' reactions and organizational attractiveness. That is, the higher the CSR performance, the lower the effect of CSR communication on observers' reactions and organizational attractiveness. Schultz et al. (2013) explain that CSR communication is an important part of CSR and that CSR is rather a process. The results presented here underline that it may be important to more thoroughly consider the process of CSR. As such, having a low CSR performance should not preempt companies to embark on the journey to improve their CSR efforts and communicate the steps along their way toward expanding their CSR performance.

Third, our study provides a new perspective to the CSR and general management literature on the role of inconsistencies for employees' and customers' reactions (e.g De Jong et al., 2018; Kim, 2019; Scheidler et al., 2019). To date, studies mainly argue for negative effects of inconsistency because it prohibits authenticity, sincerity, and credibility which reduces trust in the signal (Carlini et al., 2019; De Roeck \& Maon, 2018; Lee et al., 2019). Beyond the emphasis of signaling theory on authenticity, sincerity, and credibility, these aspects have particularly been discussed in the context of CSR communication because the main challenge of CSR lies in finding a way between hypocrisy and transparency (Du et al., 2010). The results of our study add to this literature by indicating that consistency might rival the distinctiveness of a signal. Companies that are not recognized for high CSR performance might benefit from communicating specific CSR activities to their customers or employees as CSR signals might receive greater attention as a "true newness" and might be interpreted as a signal for an improvement in corporate behavior. Future research on employee and customer reactions to CSR might benefit from integrating both consistency and distinctiveness in the elaboration on the effectiveness of CSR communication to better understand which context, content, and intensity of CSR and other communication produces positive but also negative reactions among important stakeholders. The results further point to future opportunities in differentiating the effects of inconsistencies according to the type of consistency that varies along the source of information, the type of stakeholders, and the context.

\section{Theoretical Background}

\section{A Signaling Theory Perspective on Potential Applicants' Reactions and Organizational Attractiveness}

Potential applicants are relevant to organizations as a future strategic resource, which is why organizations need to actively manage the perceptions of potential applicants and actual job seekers to attract their future workforce (Chapman et al., 2005; Gomes \& Neves, 2011). Central to firms' ability to attract talented individuals is the potential applicants' "overall evaluation of the attractiveness of the [...] organization" (Chapman et al., 2005 p. 929). In this regard, organizational attractiveness is important because it influences applicants' decision to gather and process additional information about an organization (Cable \& Turban, 2001) and affects job choice decisions (Gomes \& Neves, 2011; Greening \& Turban, 2000; Reis et al., 2017).

Research identified several mechanisms to explain how organizational attractiveness arises depending on the attributes of potential applicants and the organization. From a person-organization fit perspective, applicants prefer organizations with whom they perceive a fit between their attributes (e.g., traits, values) and an organization's attributes (Cable \& Judge, 1994, 1996; Chatman, 1989). Studies on individual attributes mainly focus on the role of personality characteristics in the emergence of organizational attractiveness, such as self-esteem, need for achievement (Turban \& Keon, 1993), openness to experience, and conscientiousness (Schreurs et al., 2009). While the attributes of applicants exist independently of the organization, the organization can actively manage its own attributes and the communication of these attributes to shape applicants' perception of organizational attractiveness (Edwards, 2010; Theurer et al., 2018). To understand how organizations can influence the perception of potential applicants and thereby shape their organizational attractiveness, signaling theory provides us with one of the most prominent perspectives (Celani \& Singh, 2011).

Signaling theory (Rynes, 1991; Spence, 1978) highlights that the communication process between the organization and potential applicants is crucial for understanding why potential applicants are (not) attracted to certain organizations (Celani \& Singh, 2011). From the perspective of signaling theory, the process of attracting applicants is strongly affected by information asymmetries influencing both organizations' and individuals' decision making (Celani \& Singh, 2011). Information asymmetry exists between a company and applicants for relevant information such as the treatment of employees within the organization (Celani \& Singh, 2011; Turban, 2001). 
To solve the asymmetry, the sender (e.g., the potential employer) can decide to communicate or signal information and the receiver (e.g., applicant) interprets the signal (Connelly et al., 2010). Moreover, the higher the asymmetry, the more likely it is that receivers will actively search for information (Fombrun \& Shanley, 1990).

The success of the signaling process between parties, such as companies and applicants depends on characteristics of the sender (e.g., honesty, observability), characteristics of the receiver (e.g., attention, interpretation), and characteristics of the signal (e.g., consistency, frequency) (Connelly et al., 2010). Applicants tend to use organizational attributes as cues about firm's intentions, actions, and values (Backhaus et al., 2002). In the process of choosing an organization to work for, potential applicants use the available information to prepare a rational choice (Miller \& Jablin, 1991). Carlini et al. (2019), thus, suggest that providing information concerning an organization's values and other firm-related attributes is beneficial for the emergence of positive organizational attractiveness, as it reduces information asymmetry.

Empirical research provides insights into different factors that explain which type of information influences organizational attractiveness in which way. According to Lievens and Highhouse (2003), there are two types of relevant information. On the one hand, organizations communicate objective, concrete, and factual attributes (e.g., pay, bonuses) that reflect an instrumental function (Lievens \& Highhouse, 2003). On the other hand, organizations communicate subjective and intangible attributes (e.g., innovativeness, prestige) that transport a symbolic function (Lievens \& Highhouse, 2003). In their study, Lievens and Highhouse (2003) find that communicating information that holds symbolic function explains organizational attractiveness beyond the effect of factual job or organization-related attributes. While companies can draw on the communication of both types of information, research has highlighted that greater potential for differentiation from competing organizations lies within the communication of attributes that possess a symbolic function (Highhouse et al., 2007; Lievens \& Highhouse, 2003). Among such types of information, research on attracting potential applicants and increasing organizational attractiveness proposes that CSR holds the greatest potential of differentiation and thereby is important for understanding applicant reactions and organizational attractiveness (e.g., Greening \& Turban, 2000; Jones et al., 2014; Turban \& Greening, 1996).

\section{The Role of CSR Communication for Potential Applicants' Reactions and Organizational Attractiveness}

CSR communication is "communication that is designed and distributed by the company itself about its CSR efforts" (Morsing, 2006). As such, companies deliberately disseminate information about issues like their treatment of minorities, use of renewable energies, or programs concerning employee volunteering (Du et al., 2010; Frostenson et al., 2011). Several mechanisms explain how communicating CSR produces positive reactions among potential applicants and contributes to organizational attractiveness. From a person-organization fit perspective, applicants feel attracted to companies that exhibit similar or compatible values to the applicants' personal values (Jones et al., 2014, 2016). Thus, potential applicants-in particular those that value aspects related to social and environmental concernstend to be drawn toward companies that communicate high levels of CSR because CSR is perceived as a way to nurture their personal values in their future work environment (Greening \& Turban, 2000; Zhang \& Gowan, 2012). Beyond value fit, signaling theory emphasizes that signals are used by potential applicants to make inferences about their potential future employer (Celani \& Singh, 2011; Jones et al., 2014). Based on these inferences, three overarching mechanisms (i.e., inferences about working environment, work climate, and other organizational attributes) explain how signals provided via CSR communication lead to positive reactions among potential applicants independent of how important CSR is to them.

First, communicating CSR-related aspects can produce a positive signal about the expected working environment provided by a company (Backhaus et al., 2002; Turban \& Greening, 1996). Based on CSR signals, potential applicants make conclusions about the expected treatment by the potential employer because CSR suggests a fair treatment of stakeholders (Aguilera et al., 2007; Jones et al., 2014). By communicating a company's relationship with internal and external stakeholders (e.g., the treatment of minorities, company's involvement with the community), companies convey information about their capabilities in filling institutional voids by creating a safe working environment and equal employment opportunities (Zhang et al., 2020). Second, potential applicants draw inferences from CSR about expected work climate in the company, which also includes the type of people who work for the company (Jones et al., 2016; Zhang \& Gowan, 2012). Third, CSR can support applicants' perceptions about the financial stability, employer's adaptability, future orientation, and potential job benefits (Jones et al., 2016; Lis, 2012). Those inferences about the company's beneficial attributes can also trigger anticipated pride in the company among potential applicants and thereby result in positive attitudes and greater organizational attractiveness (Jones et al., 2014).

Although the effect of communicating CSR on applicants' reactions and organizational attractiveness is evidenced by empirical research (e.g., Greening \& Turban, 2000; Jones et al., 2014; Zhang \& Gowan, 2012), the way organizations 
communicate with stakeholders has changed tremendously through the advent of social media (Barnett et al., 2020; Etter et al., 2019; Floreddu et al., 2014). While CSR communication in practice and research has been dominated by CSR reporting as the main communication tool, CSR communication practices have broadened and now strongly include social media (Verk et al., 2019). Signaling theory underlines that the effect of the signal on the receiver depends on the signaling context, which also includes the type of channel that messages are sent through (Connelly et al., 2010; Jones et al., 2014). In relationships marked with high information asymmetry (e.g., between an organization and potential applicant), companies draw on social media as a communications channel to signal and exchange information (Caers \& Castelyns, 2010). Results from the 'Employer Branding Global Trends Study' showed that $79 \%$ of the participating organizations prefer social media channels over career websites (64\%) and referrals (39\%) (Employer Brand International, 2014). Social media is different from traditional communication channels in providing the opportunity to directly measure feedback of the communicated content (Floreddu et al., 2014).

In the context of employer branding, Facebook played a significant role in the exchange between potential employers and potential applicants (Nikolaou, 2014; Sivertzen et al., 2013; Wazed \& Ng, 2015). Empirical research indicates that the provision of information via Facebook career pagesand especially information on specific topics in contrast to general company information-increases the number of applications companies received (Golovko \& Schumann, 2019). Facebook measures feedback based on observer reactions to a post such as likes, shares, and comments (Floreddu et al., 2014). Likes indicate a positive evaluation of and interest in the content of the communication (Saxton et al., 2019). Shares indicate that the observer evaluates the message as valuable for his/her own network of followers and thereby reflects the substantial interest of the observer in the message (Saxton et al., 2019). Although shares can reflect negative reactions to a message, shares generally tend to express a way of endorsement of a message as they become visible to peers (Hartmann et al., 2020). Comments allow observers to express their opinion with more detail and reflect the engagement of the observer in the conversation (Saxton et al., 2019). Social media is likely to introduce significant changes in the signaling process, such as the observability of the senders' activities or the distortion of the signal through the noise in the signaling environment (Eberle et al., 2013; Etter et al., 2019).

Social media communication works at different levels, which are nested in each other. First, companies publish messages in the form of single posts that focus on different topics (e.g., announcement of new positions, current employee volunteering projects). At this post-level, we can understand if the different topics (e.g., product-related vs. CSR-related content) addressed in messages posted by one company evoke different reactions among observers. Second, beyond the post-level, the single posts are nested within the respective company. Thus, comparing the communication across single posts within each company implies an organizational level that reflects a company's overall communication compared to other companies' communication. The organizational level, thus, encompasses how communicating a certain topic produces different results for different companies. At the organizational level, it is not a single post but the accumulation of all posts by a certain company on a specific topic that produces certain reactions among observers. Other studies that include analyses in the context of social media equally pointed out the conceptual importance of distinguishing the different levels in communication (e.g., Saxton et al., 2019).

\section{Post level: How CSR-related posts affect observers' reactions}

Following the arguments based on signaling theory, we propose that the effect of CSR communication via CSRrelated messages will motivate observers' reactions (i.e., likes, shares, comments) because the CSR-related message induces positive inferences about the working environment, the work climate, and general attributes of the company (e.g., financial stability). Companies use their Facebook career pages to inform potential applicants via this channel. Reading CSR messages among other company information provides the observers with the opportunity to learn about the context of the potential employer or job they are interested in. Since CSR-related messages signal a positive context, we argue that CSR-related messages will stand out and produce a more positive reaction than other content disseminated via a company's Facebook career page.

Prior research indicates that CSR-related content is considered as more significant than other employer-related content (Alnıaçık \& Alnıaçık, 2012; Kaur et al., 2015). As such, studies on future work environments found that socialrelated facets (i.e., describing the work climate and relations among colleagues) are more relevant for potential applicants than interest-related (i.e., referring to an organization's innovations and the product or services), economic-related (i.e., referring to the compensation package), or developmentalrelated (i.e., offering opportunities for future jobs) (Alnıaç1k \& Alnıaçık, 2012; Kaur et al., 2015). Thus, if CSR-related messages induce positive inferences about the work environment and work climate (independent of observers' interest in CSR itself), CSR-related messages are likely to result in positive reactions among observers.

The arguments concerning observers' positive reactions to CSR-related messages via social media are backed by 
empirical findings. Communicating CSR-related messages via Facebook showed to increase global CSR perceptions or CSR associations among general observers and potential applicants, which implies greater levels of inferences about a company's CSR engagement (Belinda et al., 2018; Fraustino $\&$ Connolly-Ahern, 2015). Moreover, Facebook was found to be able to provide richer information than solely communicating CSR via corporate websites (Belinda et al., 2018). Korschun and Du (2013) explain that media richness enables conveyance of information in various ways and expressing complex and value-laden content, which is crucial to induce virtual CSR dialogs. Beyond the ability of social media messaging to produce strong inferences about the company, a recent analysis of Twitter messages of CSR showed that these messages positively resonated with observers (Saxton et al., 2019), a finding which indicates that CSR-related messages may produce greater awareness and positive reactions among observers. Thus, based on signaling theory and empirical results in the context of social media, CSR-related posts via Facebook career pages are likely to result, first, in inferences about companies, which then are likely to translate into positive reactions among observers.

Hypothesis 1 CSR-related posts have a more positive influence on observer reactions than other posts.

\section{Organizational Level: How CSR Communication Affects Organizational Attractiveness}

In addition to an assumed positive influence of CSR-related posts on the intensity of observers' reactions, we propose that the overall number of CSR-related posts reflects CSR communication and influences organizational attractiveness. Organizational attractiveness is indicated by the overall degree of positive reactions the company receives in the form of the average number of likes, shares, and affective reactions of observers. We argue that the overall degree of reactions reflects the overall evaluation of the company because observers' aggregated reactions indicate a general favorability toward the organization as a potential employer.

Empirical research on recruitment underlines that social media communication among potential applicants is closely connected to organizational attractiveness. In their longitudinal study, Golovko and Schumann (2019) show that company posts on social media can have a positive effect on a company's attractiveness as an employer depending on the content of the posts. As such, information about the working environment had an even stronger effect on the recruitment success. Carpentier et al. (2019) find that organizational attractiveness increases after viewing organizations' social media page. They show that the attractiveness increases because of the perception (e.g., perceived organizational competence) that applicants generate from viewing the way companies communicate via their social media accounts. In their experiment, Carpentier et al. (2017) found that, compared to other recruitment channels, nurses who visited a prospective employer's Facebook page felt more attracted to working at this place (i.e., hospital). Their study showed that the increase in organizational attractiveness could mainly be explained by potential applicants' perception of social presence (i.e., the feeling of warm, friendly, and interpersonal communication) that increased when viewing the hospital's social media channel. A study by Frasca and Edwards (2017) underlines that social media communication via Facebook increases the perception of media richness and thereby leads to greater organizational attractiveness among observers of the respective channel. Thus, based on signaling theory and empirical results from recruitment studies in the context of social media, we propose that CSR communication via social media results in greater organizational attractiveness indicated by a higher total number of likes, shares, and comments.

Hypothesis 2 CSR communication via social media has a positive influence on organizational attractiveness.

\section{Inconsistency: The Interaction Between CSR Communication and CSR Performance}

While we have learned much about CSR as one of the most efficient signals in the recruitment process (Jones et al., 2014), there is still a lack in understanding how inconsistent information about a signaler affects receivers' reactions (Connelly et al., 2010). The greatest challenge in CSR communication is to achieve sincerity and trust in the signal and avoid the perception of hypocrisies among observers of CSR-related messages (Skard \& Thorbjørnsen, 2014). Thus, although CSR communication has been shown to positively relate with applicants' reactions and the overall organizational attractiveness (e.g., Greening \& Turban, 2000; Joo et al., 2016), the effect might differ when the signal is distorted by information perceived as inconsistent. According to signaling theory, the signaling effectiveness depends on the signal's consistency, which is the coherence of a message among various dimensions and channels from one source (Connelly et al., 2010; Gao et al., 2008). Individuals associate more attributes, and associate them more automatically, with entities perceived as members of more unified, coherent, and consistent category (Fischer \& Reuber, 2007). However, signals are inherently diffuse and ambiguous (Fombrun \& Shanley, 1990), which might have even been amplified by social media (Etter et al., 2019).

Inconsistencies between qualities of the sending company and the message transmitted by the signal negatively impact the reliability of the signal (Connelly et al., 2010). Consequently, the receiver's perception of a positive signal 
can be reversed when the receiver gets confused by conflicting signals (Connelly et al., 2010; Fischer \& Reuber, 2007). Applied to the CSR context, inconsistency might distort the signaling process of CSR-related posts. The content of CSR posts might be perceived as unreliable, inauthentic, untrustworthy, and irritating if the content of the communication on social media does not fit the overall CSR performance of the company. These mechanisms are similar to the effects of greenwashing, which implies symbolic information emanating from within a company without substantive actions (Walker \& Wan, 2012). However, inconsistencies between CSR communication and performance does not necessarily mean that CSR communication lacks substantive actions. A company could show a low overall CSR performance while substantively starting to invest in CSR activities and communicating these activities (Schultz et al., 2013). During the process of improving the overall CSR performance, there might be a period where the overall CSR performance does not yet reflect the CSR activities communicated by the company. Thus, inconsistencies might occur not only due to greenwashing but also due to companies transitioning to a higher CSR performance (Schultz et al., 2013).

Although research on applicants' reactions has not yet considered the negative effect of inconsistencies in CSR communication, studies on consumer reactions to CSR underline that the positive effect of CSR communication on stakeholders' reactions might be bounded to its consistency. In this vein, studies showed that incongruence between source and brand (Skard \& Thorbjørnsen, 2014), between message and company purpose (White \& Willness, 2009), and inconsistencies of former CSR reputation and a future CSR crisis worsen consumers' attitude toward the company (Gistri et al., 2019). Similarly, recent research on employee reactions to CSR underlines that inconsistencies between internal and external CSR efforts increase employee turnover (Scheidler et al., 2019). Inconsistent CSR information might produce negative attitudes and behaviors because inconsistency in perceptions of stakeholders elicits corporate hypocrisy - that is, the belief that a firm claims to be something it is not (Wagner et al., 2009). Thus, it can be expected that a low CSR performance limits the positive effects of CSR communication.

Companies with a low CSR performance could be confronted with negative feedback, as signaling CSR could lose its credibility, which might be particularly pronounced when communicating on social media. Social media is based on a two-way symmetric interaction concept (Lyon \& Montgomery, 2013). On one side, this provides an ideal opportunity for organizations to get into direct contact with potential stakeholders. On the other side, direct contact is less controllable than traditional media (Zerfass \& Schramm, 2014). Regarding signaling theory, the two-way symmetric interaction via social media enables receivers to give direct and public feedback (Etter et al., 2019). Assuming a sender's negative qualities to interfere in the signaling process, companies face the risk of adverse public reactions from observers. Consequently, CSR-related posts submitted by companies with a low CSR performance are proposed to be less positively perceived than from companies with a high CSR performance due to a weaker signal fit. Along these lines, we also argue that a low CSR performance will weaken the effect of the overall CSR communication on organizational attractiveness.

Hypothesis 3 The positive influence of CSR-related posts on observer reactions is decreasing the lower the overall CSR performance of a company.

Hypothesis 4 The positive influence of CSR communication on organizational attractiveness is decreasing the lower the overall CSR performance of a company.

\section{Methodology}

To test our research model concerning the effects of CSR communication, we performed a social media web scraping study, conducted a content analysis on the scarped data, and combined the data with secondary data. A web-scraping study has the advantage of gathering data on both the social media communication of a firm as well as observers' reactions to this communication (Foster et al., 2016; Landers et al., 2016). Scraping of both forms of data (firm communication and observers' reactions) implies an objective, non-obtrusive, and ecologically valid way of measurement (Foster et al., 2016). Moreover, the chronological sequence of posts followed by reactions provides a strong support for the causal relevance of the posts (Foster et al., 2016).

\section{Sample}

The sample of companies was chosen following three criteria that ensured the representativeness of the sample and enabled us to derive indicators for the variables included in our research model. First, companies were listed among the Fortune 500 most successful companies of 2017. We could, therefore, expect that a reasonable amount of interactions between organizations and potential applicants was recorded via social media. Second, only companies that operated a Facebook career page with content in English were retained. We selected Facebook career pages as they historically have the broadest reach, thereby exemplifying social media communication and recruitment communication well (Golovko \& Schumann, 2019; Kaplan \& Haenlein, 2010). Although Facebook has shown a decrease in its reach, it has the most substantial historical data (Wilson et al., 2012) and 


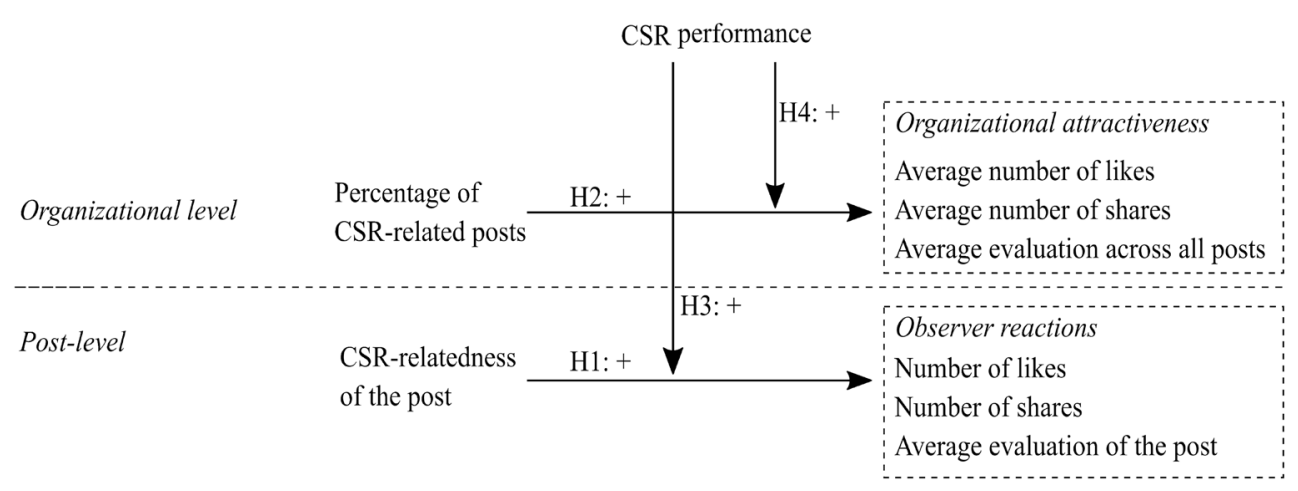

Fig. 1 Conceptual model

is strategically used by companies as a recruitment channel (Golovko \& Schumann, 2019). Therefore, we decided to scrape all data from the start of the career pages (earliest in 2004) until June 2018. Third, to analyze the interaction effect of CSR communication with the overall CSR performance, we only included companies that were ranked via the CSRHub database, one of the most extensive databases for CSR performance, which includes ratings of over 17,000 companies from more than 140 countries (CSRHub, 2019). Given that Facebook web-scraping is limited, the sample focused on providing heterogeneity in our moderating variable CSR performance, which is why companies with the lowest and also the highest CSRHub scores were retained. Based on the presented criteria, 58 organizations with a total number of 67,189 posts and 15,323,489 corresponding observers' reactions (including likes, shares, comments) were included in the final sample.

\section{Variables}

The data was scraped by the Facebook Application Programming Interface (API). Only publicly available data was obtained without the personal information of the observers. The data included companies' posts and observers' reactions including the corresponding number of likes, number of shares, and written comments. The structure of the data differentiates between a post level and an organizational level (Fig. 1) because micro- and macro-levels within a multilevel framework may not necessarily show consistent patterns of relationships (Klein \& Kozlowski, 2000). The post level referred to a single post and the observers' reactions per post. The organizational level represented aggregated CSR communication and the reactions to posts on an average level. By differentiating the multi-level structure, our study prevents conducting the atomistic fallacy (i.e., falsely transferring effects on a micro level to those of a macro level) as well as the ecological fallacy (i.e., falsely transferring effects of a macro level onto the micro level), which are common threats to multilevel frameworks (Diez Roux, 2002) and in big data applications (Hernandez et al., 2015).

\section{Independent Variables}

CSR-related posts (post level) were measured via a two-step content analysis (Fig. 2) which resulted in a binary variable indicating whether the post had a CSR content (coded as 1) or not (coded as 0). In a first step, we generated a codebook with 89 keywords regarding categories based on the Kinder, Lydenberg, and Domini (KLD) index, which is commonly used in CSR literature (e.g., Chin et al., 2013; Turban \& Greening, 1996; Wang \& Berens, 2015). We drew on the following six categories proposed by the KLD framework (sample keywords in parentheses): support for the community (keywords: e.g., minority, disabled, gay), environment (keywords: e.g., planet, renewable, recycling), human rights (keywords: e.g., union relations, humanity, labor rights), corporate governance (keywords: e.g., political involvement, fair compensation, environmental record), employee relations (keywords: e.g., health program, retirement, employee involvement), and product/services (keywords:

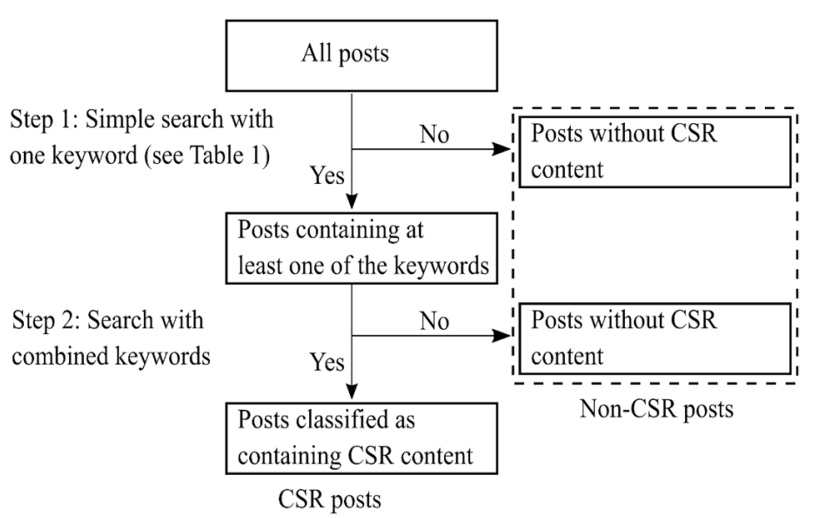

Fig. 2 Flow chart depicting the coding process 
e.g., innovation, quality program, $R \& D)$. Based on these keywords we rated all posts as either CSR-related or not.

In the second step, we screened the CSR-related posts by checking for ambiguities in the keyword results. For example, terms such as "environment" or "climate" used as keywords in the first step might also occur in posts about "working environment" or "working climate" without reference to CSR. Therefore, we combined the keywords with ambiguous results with an additional keyword to refine the coding of CSR-related posts. For example, "climate" with the related words "planet," "environment," or "change" clarified whether a post was indeed CSR-related. Moreover, we screened all CSR-related posts for keywords that identified the post as "not CSR-related" (e.g., "hiring," "top job," "job vacancy," "apply now," and "Merry Christmas").

One example of a CSR-related post was: "[Group X] helps make [the company] a great place to work by identifying opportunities to educate and inform employees about LGBT issues and opportunities. The group also makes [the company] more visible within the LGBT community at large. Locally in Seattle, [group x] sponsors the PRIDE Parade and organizes participation in the AIDS Walk." One example of a post that was not CSR-related: "Want to build a career in Finance? Check out this blog to see how [the company] supports Finance interns fast-track their career!".

CSR communication (organizational level) was measured as the percentage of CSR-related posts compared with all posts on the Facebook career page of each company.

\section{Dependent Variables}

Observer reactions (post-level) were measured by the number of likes, the number of shares, and the average evaluation of the post across all written comments. The evaluation of the comments $(N=214,884)$ was measured by a sentiment analysis that was performed using the Natural Language API provided by the Google Cloud. ${ }^{1}$ The score of the sentiment analysis expresses the emotional tendency of a text from negative $(-1)$ to positive $(+1)$ emotions. As an example, the comment "Don't work for a place that uses rack and stack for raises or always fires the bottom 5\% every year" would result in an evaluation of -0.9 , whereas the comment "The culture at this company encourages innovation, diversity and work life balance. Amazing!" would result in an evaluation score of +0.9 . The Natural Language API by Google Cloud provides a machine-learning approach —or sometimes called supervised learning approach - to sentiment analysis. In contrast to often used, lexicon-based approaches which rely on a dictionary of opinion words, machine-learning approaches root in a manually classified training data set,

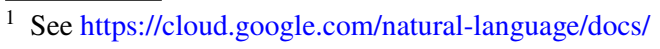

which trains classifiers to learn by examples instead of lexicon words (Dhaoui et al., 2017). Machine-learning approaches have shown greater effectiveness and are more commonly used than lexicon-based approaches (Etter et al., 2016; Pang et al., 2002).

Organizational attractiveness (organizational level) was calculated by the average number of likes and shares for each company, as well as the average sentiment a company has received in comments on their posts. Empirical research has shown that social media communication by companies affects observers' perception of the company (Carpentier et al., 2017). Social media messaging also affects potential applicants' intention to apply (Sivertzen et al., 2013), and the recruitment success, as measured by the number of applications received (Golovko \& Schumann, 2019). Thus, activities including likes, shares, and comments among observers of Facebook career pages represented a proxy for organizational attractiveness as they express evaluative judgements about an organization's activities and affect potential applicants' interest in the company as an employer.

\section{Moderating Variable}

CSR performance (organizational level) was measured by combining the web-scraped data with the CSRHub score per company (CSRHub, 2020), previously used by Arminen et al. (2018) and Lin et al. (2019). The CSRHub score ranges from 0 (=low CSR performance) to 100 (=high CSR performance). The score for each company is based on 643 data sources mainly by responsible investment consultancies and nongovernmental organizations (e.g., Global Reporting Initiative; MSCI, including ESG Intangible Value Assessment, ESG Impact Monitor, and ESG Carbon Metrics; and Trucost). The CSRHub score aggregates data into four main categories and twelve subcategories: engagement in community (community development and philanthropy; product; human rights and supply chain), employees (compensation and benefits; diversity and labor rights; training, health, and safety), environment (energy and climate change; environment, policy \& reporting; resource management), and governance (leadership ethics; board composition; transparency and reporting).

\section{Control Variables}

At the organizational level, we further controlled for companies' attachment to the $\mathrm{B} 2 \mathrm{C}$ sector (business-to-customer $=1$; versus business-to-business sector $=0$ ). This measure accounts for the fact that B2C companies communicate more intensively via social media (Swani et al., 2014). Moreover, we controlled for the industry of the respective company based on the North American Industry Classification System. 


\section{Analytical Procedures}

Social media analyses present unique challenges regarding the data and necessary analytical procedure (Kern et al., 2016). In particular, the variety of data types (e.g., count data versus semi-continuous data) with varying distributional characteristics demand attention in that they cause overdispersion and zero-inflation of the count variables and extreme nonnormality of the semi-continuous variables (Blevins et al., 2015). To account for overdispersion, zeroinflation, nonnormality, and the multi-level structure, we applied generalized mixed-effects models at the post level as well as a gamma generalized linear model and a robust regression at the organizational level (see Table 1 for an overview).

At the post level, we analyzed all hypotheses with mixed effects models (Hox et al., 2017). In particular, generalized mixed-effects models were necessary for the number of likes and the number of shares as dependent variables. These variables are count variables and do not match the assumptions inherent in traditional regression analyses (Atkins \& Gallop, 2007; Blevins et al., 2015). Generalized (mixed-effects) models consider the distribution of count variables with a Poisson model. However, count data often diverge from the Poisson distribution, which was true in our case. These divergences exist in form of (A) an overdispersion (i.e., an extreme variance) and (B) an extreme number of zeros (the "zero-inflation"). These problems can be handled by estimating a negative-binomial distribution (instead of a Poisson distribution) as well as zero-inflated models (with either distributions). To select the appropriate model, we followed recommendations from the literature and compared the fit of a variety of models including the basic Poisson model, the basic negative-binomial model, the zero-inflated Poisson model, the zero-inflated negative-binomial models, and the hurdle model (Blevins et al., 2015; Cameron \& Trivedi, 2013). From the comparison of the models, the hurdle model showed the best fit. The hurdle model separates the observed distribution into a zero- versus non-zero part (i.e., getting no like versus getting at least one like) and a part with the positive numbers. For both parts, it was possible to use the same or different predictors to estimate the occurrence of likes versus the number of likes beyond the mere occurrence. The average evaluation of the post, in contrast, represented a semi-continuous variable that was analyzed by a general linear mixed-effects model (Hox et al., 2017).

At the organizational level, the average number of likes and shares was substantially skewed and strongly violated the assumptions of homoscedasticity and normal errors. As a consequence, we estimated a gamma generalized linear model (Barber \& Thompson, 2004; Ng \& Cribbie, 2017). As the deviations from model assumptions were more modest in the case of the average post evaluation, we estimated a robust regression model that reweights the residuals such that outlying residuals do not bias the regression coefficient (Berk, 1990).

\section{Results}

\section{Descriptive Statistics}

Table 2 shows the descriptive statistics of the post-level variables. The specific characteristics of social media data become evident in the distributional statistics of the model variables. Most apparent are the substantially skewed distributions for the number of likes and number of shares and the enormous kurtosis (indicating a massive peak of zero values). In contrast, the average post-evaluation shows nonsubstantial deviations from the normal distribution. Due to these skewed distributions, we depict the Spearman rank correlations. As the right part of the sample shows, the number of likes and the number of shares were highly correlated $(r=0.68, p<0.01)$, indicating that can be expected to reflect common observer reactions of the post. The table further shows that the number of likes and shares were negatively, albeit only weakly, related to the CSR content.

Table 3 shows the descriptive statistics for the organizational level data. The mean percentage of CSR content posted by companies was $8.72 \%(\mathrm{SD}=6.39)$. In contrast to the level of individual posts, the CSR content correlated substantially and positively with the number of likes $(r=0.52$, $p<0.01)$, number of shares $(r=0.35, p<0.01)$, and the average evaluation of their posts $(r=0.32, p<0.05)$, pointing to the reduction of noise by aggregating post-level data. The mean of the CSR performance was 54.17, with an associated range between 40 (low CSR performance) to 68 (high CSR performance). As the table shows, firms with a high CSR performance posted substantially more CSR content ( $r=0.37, p<0.01$ ), thus, supporting the validity of our CSR coding procedure and had substantially higher number of likes $(r=0.49, p<0.01)$ and number of shares $(r=0.35$, $p<0.01)$. In contrast, the post evaluation did not differ compared with firms with a lower CSR performance $(r=0.13$, $p>0.05)$. Analogous to the post-level, the number of likes and number of shares had severe skewness and kurtosis, making traditional regression analyses inappropriate.

\section{Test of Hypotheses on the Post Level $(\mathrm{H1}, \mathrm{H3})$}

\section{Number of likes}

As Table 2 shows, the number of likes strongly deviated from the assumed Poisson distribution. Hence, we compared a series of models that differed in the presumed error distribution and explicit consideration of the inflated zero-part of the variable. Table 4 shows the fit statistics for the diverse 


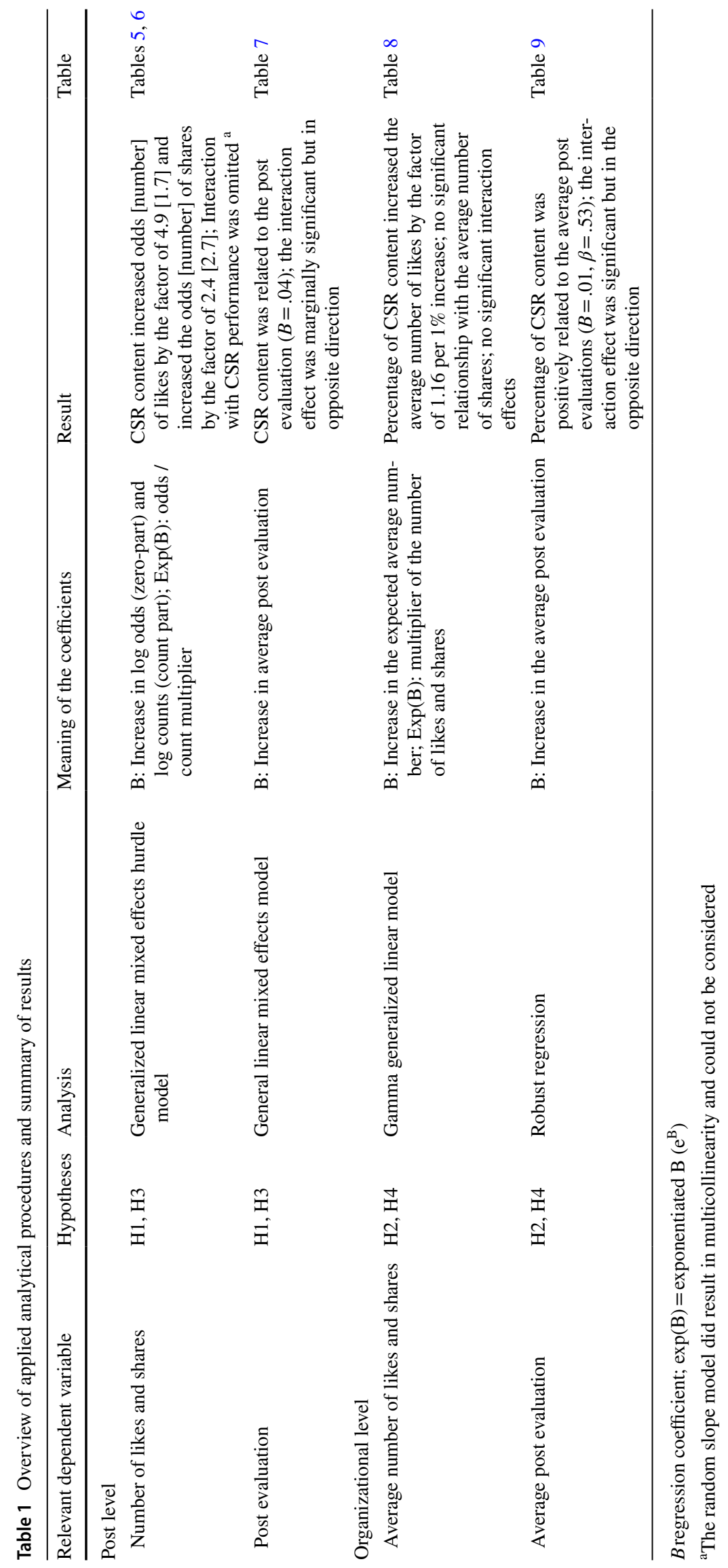


Table 2 Descriptive statistics of post level variables

\begin{tabular}{lllrrrrr}
\hline & M (SD) & Median & Skew & Kurtosis & (1) & (2) & (3) \\
\hline (1) CSR-relatedness of the post & $0.08(0.28)$ & 0.00 & 3.01 & 7.05 & & & \\
(2) Number of likes & $181.14(2343.77)$ & 7.00 & 24.99 & 806.80 & $-0.15^{* *}$ & & \\
(3) Number of shares & $4.41(31.63)$ & 1.00 & 95.83 & $15,099.43$ & $-0.08^{* *}$ & $0.68^{* *}$ & \\
(4) Average post evaluation & $0.28(0.29)$ & 0.24 & 0.17 & 0.18 & $0.05^{* *}$ & $0.03^{* *}$ & 0.01 \\
\hline
\end{tabular}

$M$ mean; $S D$ standard deviation

${ }^{*} \mathrm{p}<0.05 ;{ }^{*} \mathrm{p}<0.01 ; N: 67,189$ except for the average evaluative value of the comments $(N=20,119)$

${ }^{\mathrm{a}} 0=$ no CSR-content vs. $1=$ CSR-content; correlations are Spearman rank correlations

Table 3 Descriptive statistics of organizational-level variables

\begin{tabular}{lcrrrrrrr}
\hline & M (SD) & Median & Skew & Kurtosis & (1) & (2) & (3) & (4) \\
\hline (1) Percentage of CSR communication & $8.72(6.39)$ & 7.13 & 0.79 & -0.11 & & & & \\
(2) CSR performance & $54.17(7.66)$ & 57.00 & -0.52 & -1.22 & $0.37^{* *}$ & & \\
(3) Average number of likes & $145.92(610.08)$ & 14.35 & 6.42 & 42.74 & $0.52^{* *}$ & $0.49^{* *}$ & \\
(4) Average number of shares & $4.53(5.68)$ & 2.85 & 2.49 & 8.03 & $0.35^{* *}$ & $0.35^{* *}$ & $0.85^{* *}$ \\
(5) Average evaluation across all posts & $0.28(0.15)$ & 0.27 & 1.62 & 6.97 & $0.32^{*}$ & 0.13 & 0.09 & -0.13 \\
\hline
\end{tabular}

$M$ mean; $S D$ standard deviation; $N=58$

$* \mathrm{p}<0.05 ; * \mathrm{p}<0.01$

Table 4 Comparison of generalized linear mixed effects models (preparation for testing H1, H3)

\begin{tabular}{|c|c|c|c|c|c|c|c|c|}
\hline \multirow[t]{2}{*}{ Distribution } & \multicolumn{4}{|c|}{ Number of likes } & \multicolumn{4}{|c|}{ Number of shares } \\
\hline & AIC & LL & Deviance $^{a}$ & DF & AIC & LL & Deviance $^{\mathrm{a}}$ & DF \\
\hline Poisson & $54,171,776$ & $-27,085,882$ & $54,171,764$ & 59,896 & $1,044,841$ & $-522,414$ & $1,044,829$ & 59,896 \\
\hline Negative binomial $1^{\mathrm{a}}$ & 536,405 & $-268,196$ & 536,391 & 59,895 & 248,656 & $-124,313$ & 248,626 & 59,887 \\
\hline Negative binomial 2 & 498,143 & $-249,065$ & 498,129 & 59,895 & 248,519 & $-124,244$ & 248,489 & 59,887 \\
\hline Zero-inflated Poisson & $52,673,146$ & $-26,336,564$ & $52,673,128$ & 59,893 & 822,643 & $-411,303$ & 822,607 & 59,884 \\
\hline Zero-inflated negative binomial 1 & 535,526 & $-267,744$ & 535,488 & 59,883 & 246,268 & $-123,115$ & 246,230 & 59,883 \\
\hline Zero-inflated negative binomial 2 & 495,072 & $-247,525$ & 495,050 & 59,891 & 244,810 & $-122,386$ & 244,772 & 59,883 \\
\hline Hurdle model & 478,409 & $-239,193$ & 478,387 & 59,891 & 241,367 & $-120,664$ & 241,329 & 59,883 \\
\hline
\end{tabular}

AIC Akaike information criterion; $L L \log$ likelihood; $D F$ degrees of freedom; the tested model were random intercepts plus fixed slopes models

a estimated variance in GLMM $1=\phi \mu$ versus in the GLMM $2=\mu / 1+\mathrm{u} / \mathrm{k}$

models. The left panel of the table shows that the last model, the hurdle model, showed the best fit and, thus, was chosen.

Table 5 shows the results of the hurdle model. As introducing a random slope in addition to a random intercept had tremendous negative consequences (i.e., coefficients with opposing signs and standard errors increased by a factor of 10), we kept the random intercept model as the final model and had to refrain from testing the cross-level interaction hypothesis. The left panel of the table depicts the zero-inflation part, in which the independent variables predict whether a company receives at least one like. The baseline odds of receiving at least one like for a non-CSR-related post were 0.77. By posting CSR content, these odds were increased by the factor of $4.869(B=1.583, p<0.01)$, supporting $\mathrm{H} 1$. Additionally, the cross-level effect of CSR performance was significant $(B=-0.066, p<0.01)$, although the effect size was too small to be interpreted. The right panel, showing the effects of the count part of the model mimic those of the zero-inflation part: The mean number of likes for non-CSR posts was 22.874 and it is increased by the factor of 1.682 when posting $C S R-c o n t e n t(B=0.520, p<0.01)$. This again, supports our H1.

\section{Number of Shares}

The results of the model comparison for the count mixedeffects models show that the hurdle model has the best fit (Table 4). The results of the hypothesis tests with the hurdle model are shown in Table 6. Analogous to the number of likes, posting CSR content increased the odds of having 
Table 5 Post-level analyses: Effects of a post's CSR content on the number of likes (H1 and $\mathrm{H} 3$ )

Table 6 Post-level analyses: effects of a posts' CSR content on the number of shares (H1 and $\mathrm{H} 3$ )

\begin{tabular}{llllrr}
\hline & \multicolumn{2}{l}{ Zero-inflation model } & & Count model & \\
\cline { 2 - 3 } & $\mathrm{B}(\mathrm{SE})$ & $\operatorname{Exp}(\mathrm{B})$ & & $\mathrm{B}(\mathrm{SE})$ & $\operatorname{Exp}(\mathrm{B})$ \\
\hline Level 1 & $-2.562(0.221)^{* *}$ & 0.772 & & $3.130(0.86)$ & 22.874 \\
Intercept & $1.583(0.039)^{* *}$ & 4.869 & & $0.520(0.059)^{* *}$ & 1.682 \\
CSR-relatedness of the post & & & & \\
Level 2 & $-0.066(0.029)^{*}$ & 0.936 & & $0.132(0.033)^{* *}$ & 1.14 \\
CSR performance & & & & \\
Additional information & 0.62 & & & \\
ICC & & & & & \\
\hline
\end{tabular}

The models are generalized mixed effects hurdle models; $N_{\text {Posts }}=59,902 ; N_{\text {Organizations }}=51$

$* \mathrm{p}<0.05 ; * * * \mathrm{p}<0.01$

${ }^{a}$ ICCs cannot currently be calculated for models addressing a zero-inflation. The printed ICC was estimated with a GLMM with negative binomial distribution and may, thus, overestimate the true ICC

\begin{tabular}{|c|c|c|c|c|}
\hline & \multicolumn{2}{|c|}{ Zero-inflation model } & \multicolumn{2}{|l|}{ Count model } \\
\hline & B (SE) & $\operatorname{Exp}(B)$ & B (SE) & $\operatorname{Exp}(B)$ \\
\hline \multicolumn{5}{|l|}{ Level 1} \\
\hline Intercept & $0.109(0.191)$ & 1.115 & $-15.818(315.960)$ & 0.000 \\
\hline $\begin{array}{l}\text { CSR-relatedness of the post } \\
\text { Level } 2\end{array}$ & $0.879(0.033)^{* *}$ & 2.408 & $1.000(0.066)^{* *}$ & 2.718 \\
\hline CSR performance & $-0.044(0.025)$ & 0.957 & $0.077(0.018)^{* *}$ & 1.080 \\
\hline \multicolumn{5}{|l|}{ Additional information } \\
\hline $\mathrm{ICC}^{\mathrm{a}}$ & 0.51 & & & \\
\hline Pseudo R-square & 0.01 & & & \\
\hline
\end{tabular}

The models are generalized mixed effects hurdle models; $N_{\text {Posts }}=59,902 ; N_{\text {Organizations }}=51$

$* \mathrm{p}<0.05 ; * * * \mathrm{p}<0.01$

${ }^{a}$ ICCs cannot currently be calculated for models addressing a zero-inflation. The printed ICC was estimated with a GLMM with negative binomial distribution and may, thus, overestimate the true ICC the post shared by the factor of $2.408(B=0.879, p<0.01)$ and the number of shares by the factor of $2.718(B=1.000$, $p<0.01$ ), thus supporting $\mathrm{H} 1$.

\section{Evaluation of the Post}

The final model on the post level was a traditional general linear mixed-effects model for which, due to the much lower complexity, the random intercept model, the random slope model, and the model with an estimate cross-level interaction could be estimated. Table 7 shows the model without and with a cross-level product. The table shows the first-order effect of CSR-relatedness and the interaction effect. The first-order effect was significant $(B=0.038, p<0.01)$, supporting $\mathrm{H} 1$. The interaction was only significant at an error rate of $10 \%$. The plot of the interaction effect (see Fig. 3, left panel), however, showed the opposite of what we had hypothesized, as there was a slight tendency of CSR postings to result in more positive evaluations, particularly for firms with a low CSR performance. From this perspective, H3 was rejected.
Table 7 Post-level analyses: effects of a posts' CSR content on the post-evaluation (H1 and $\mathrm{H} 3$ )

Random intercept Cross-level interaction and random slope

Level 1

$\begin{array}{lll}\text { Intercept } & 0.240(0.04)^{* *} & 0.238(0.04)^{* *} \\ \begin{array}{l}\text { CSR-relatedness of the } \\ \text { post }\end{array} & 0.038(0.01)^{* *} & 0.043(0.01)^{* *}\end{array}$

Level 2

\begin{tabular}{lll} 
CSR performance & $0.002(0.00)$ & $0.001(0.00)$ \\
Cross-level interaction & & $-0.003(0.00)^{\dagger}$ \\
CSR performance $\mathrm{x}$ & & \\
$\quad \begin{array}{l}\text { CSR-relatedness of } \\
\text { the post }\end{array}$ & & \\
Additional information & & 0.06 \\
ICC & 0.06 & 0.01 \\
Pseudo R-square & 0.01 & \\
\hline
\end{tabular}

The models are linear mixed effects models

${ }^{\dagger} \mathrm{p}<0.10, * \mathrm{p}<0.05, * * \mathrm{p}<0.01$ 
Fig. 3 Plots of the moderator effects of CSR performance on the relationship between CSR content of the post and its evaluation (left panel) and percentage of CSR communication and average post $(\mathrm{H} 3, \mathrm{H} 4)$
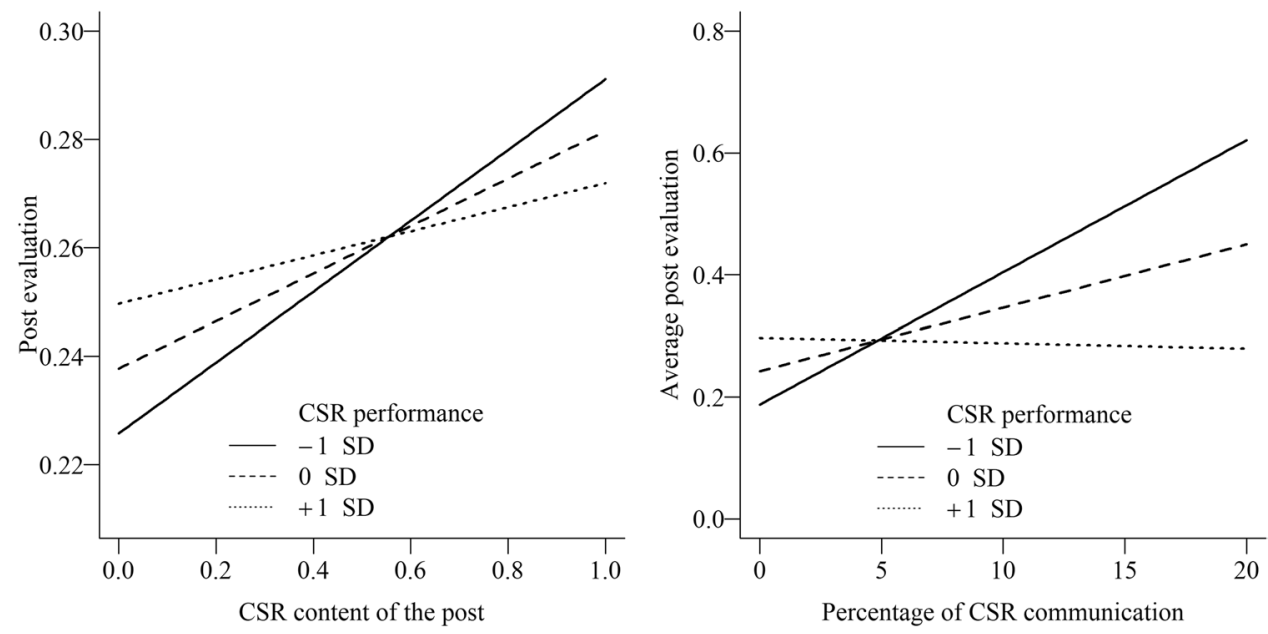

\begin{tabular}{|c|c|c|c|c|}
\hline & \multicolumn{2}{|c|}{ Average number of likes } & \multicolumn{2}{|c|}{ Average number of shares } \\
\hline & $\mathrm{B}(\mathrm{SE})$ & $\operatorname{Exp}(B)$ & $\mathrm{B}(\mathrm{SE})$ & $\operatorname{Exp}(B)$ \\
\hline Intercept & $2.330(.728)^{* *}$ & 10.28 & $0.621(0.591)$ & 1.85 \\
\hline Percentage of CSR content & $0.149(.046)^{* *}$ & 1.16 & $0.047(0.037)$ & 1.05 \\
\hline CSR performance & $0.148(.052)^{* *}$ & 1.16 & $0.088(0.041)^{*}$ & 1.09 \\
\hline $\begin{array}{l}\text { CSR performance x Percentage } \\
\text { of CSR content }\end{array}$ & $-0.007(.007)$ & 0.99 & $-0.007(0.006)$ & 0.99 \\
\hline
\end{tabular}

The models are generalized linear gamma models

${ }^{*} \mathrm{p}<0.05, * * \mathrm{p}<0.01 ; \mathrm{N}=58 ; \mathrm{B} 2 \mathrm{C}$ (business-to-customer segment) and industry were used as control variables; the pseudo R-square is McFadden's version
Table 8 Organizational level analyses: effects of CSR communication on the average number of likes and shares ( $\mathrm{H} 2$ and $\mathrm{H} 4$ )

\section{Summary of the Post-Level Analyses}

In total, all three regression analyses showed a consistent support for $\mathrm{H} 1$, which stated that CSR-related posts receive increased positive observer reactions reflected the number of likes, shares, and more positive emotional reaction. In contrast, we rejected $\mathrm{H} 3$ as the interaction plot for the evaluations of the posts indicates the opposite of what we had expected.

\section{Test of Hypotheses on the Organizational Level (H2, H4)}

\section{Average Number of Likes}

Analogous to the data at the post level, the organizational level variables were strongly skewed and highly kurtotic, violating basic assumptions of homoscedasticity and normality of the residuals (Table 3 ). Hence, we estimated a generalized gamma model, which assumes a gamma distribution as the appropriate error distribution. In addition, we applied a log link that facilitates the interpretation of the exponentiated regression coefficients like the receding analyses. Table 8 (left panel) shows that the percentage of CSR content was positively associated with the average number of likes $(B=0.149, p<0.01)$ with an associated frequency multiplier of 1.16 per $1 \%$ increase. Thus, $\mathrm{H} 2$ was supported. In contrast, there was no indication of an interaction effect, thus not supporting $\mathrm{H} 4$.

\section{Average Number of Shares}

In contrast to the number of likes, the generalized gamma model did not result in an effect of CSR communication on the number of shares, contradicting H2. Again, there was no evidence of an interaction effect of CSR performance; thus, $\mathrm{H} 4$ is rejected.

\section{Average Post Evaluation}

As the average post evaluation was approximately normally distributed, we estimated an ordinary least squares regression but corrected for the slight nonnormality of the residuals. Table 9 shows a significant relationship between the percentage of CSR content and the average post evaluation 
Table 9 Organizational level analyses: effects of CSR communication on average post evaluation ( $\mathrm{H} 2$ and $\mathrm{H} 4)$

\begin{tabular}{llr}
\hline & B (SE) & \multicolumn{1}{r}{$\beta$} \\
\hline Intercept & $0.242(0.040)^{* *}$ & \\
Percentage of CSR content & $0.010(0.003)^{* *}$ & 0.53 \\
CSR performance & $0.008(0.003)^{* *}$ & 0.48 \\
$\begin{array}{ll}\text { CSR performance } \times \text { Percentage } \\
\text { of CSR content }\end{array}$ & $-0.002(0.000)^{* *}$ & -0.01 \\
\hline
\end{tabular}

The model is a robust regression

$* \mathrm{p}<.05, * * \mathrm{p}<.01 ; \mathrm{N}=58 ; \mathrm{B} 2 \mathrm{C}$ (business-to-customer segment) and Industry were used as control variables

( $B=0.01, p<0.01)$, associated with a substantial standardized estimate $(\beta=0.53)$. Hence, $\mathrm{H} 2$ was supported. In contrast to the number of likes and shares (and mimicking results from the post level), we found a significant interaction effect. The right panel of Fig. 3, however, shows the same pattern found on the post level: there is a positive relationship between the percentage of CSR content only for low CSR performance firms but not for high CSR performance firms. Thus, $\mathrm{H} 4$ was not supported.

\section{Summary of the Organizational Level Analyses}

In total, two of three regression analyses showed support for $\mathrm{H} 2$ because a significant relationship between CSR communication and number of likes and the average post-evaluation could be detected. In contrast, the regression coefficient was non-significant in the case of number of shares. Moreover, we rejected the interaction hypothesis $\mathrm{H} 4$ because the interaction effects were non-significant for the number of likes and shares but significant but opposite for the average postevaluation-the lower the CSR performance the greater the positive effect of CSR communication on organizational attractiveness.

\section{Discussion}

Since the 1990s, research on the intersection between CSR and applicants' reactions as well as organizational attractiveness has shown that CSR helps to attract potential applicants (e.g., Turban \& Greening, 1996; Zhang \& Gowan, 2012). As such, CSR has been interpreted as an effective signal to communicate with potential applicants. Recently, however, research indicates that CSR communication may not always yield positive results (e.g., Donia et al., 2019; Gistri et al., 2019; Scheidler et al., 2019). In this paper, we investigated a missing part of the widely applied signaling theory to the relationship between CSR and potential applicants' reactions as well as organizational attractiveness by examining how observers and potential applicants react to inconsistencies between CSR communication and the overall CSR performance. To this end, we analyzed the effect of over 67,000 posts on Facebook career pages by 58 Fortune 500 companies and combined the data with CSRHub score for CSR performance.

First, the results substantiate the positive relationship between CSR communication and potential applicants' reactions as well as organizational attractiveness. Even though the average percentage of CSR content across all companies was only $8.72 \%$, increasing CSR content by $1 \%$ would increase the number of likes by a factor of 1.16. Although this seems non-substantial, an extrapolation implies that increasing CSR content by $10 \%$ would result in an increase of $45 \%$ in the number of likes. This has implications for social media research. While social media research has become popular in recent years (Azucar et al., 2018; Conway \& O'Connor, 2016; Kern et al., 2016), organizational research using big data drawn from social media is still in an emerging stage (Tonidandel et al., 2018; Wenzel \& Van Quaquebeke, 2018). Beyond its focus on the substantive research issue, the present work represents a case study of potential ways to conduct a social media study of datarelated or statistical problems that researchers must expect from data in a social media context. Most importantly, the distributions of the model variables gathered from social media can be expected to severely depart from theoretically expected distributions, as was the case in our study. Combined with the inherent multi-level structure, these characteristics lead to the requirement for sophisticated analytical procedures. This study advances social media research along with recent theoretical advances concerning the importance that social media introduces to an organization's relationships with its stakeholders (Etter et al., 2019).

Second, our analyses did not support our hypotheses that a weak CSR performance would diminish the effect of CSR communication on observers' reactions and organizational attractiveness. Instead, our results indicate the opposite: a low CSR performance strengthened the effect of CSR communication on the affective evaluation per post as well as the average affective evaluation of posts (Fig. 3). While care is warranted not to overinterpret these exceptional effects, the pattern at least suggests that particularly companies with low CSR performance could benefit from posting CSR content to promote their CSR activities. The results further suggest that firms with high CSR performance do not benefit more from posting CSR content than other content on social media (e.g., seasonal greetings, general company information). 


\section{Potential Explanations and Suggestions for Future Research}

\section{Distinctiveness Versus Inconsistencies in CSR Communication}

Regarding the unexpected findings concerning the enhancing effect of a low CSR performance, we offer three potential explanations why potential applicants might react positively to CSR communication of companies with a weak CSR performance. First, distinctiveness in messaging could be more important than authenticity, particularly in a content-rich messaging environment such as social media. Researchers investigating the effect of consistency versus inconsistency in CSR signaling often assume that receivers will evaluate messages depending on the perceived authenticity of the CSR message (Joo et al., 2016; Pérez, 2019; Scheidler et al., 2019; Wagner et al., 2009). Currently, however, CSR communication might be strongly affected by diminishing returns in its perception as being distinctive. The information processing perspective (Crocker et al., 1984; Fiske \& Taylor, 1991) poses that information will be processed and might change attitudes when it is distinct from prior information received by the observer. Thus, due to the information overload inherent in social media communication, distinctiveness might outweigh authenticity; hence, external stakeholders, such as potential applicants, perceive CSR communication positively when sent by companies that are not yet known for high CSR performance. This could be fruitful research avenue for future research to examine the mechanisms that lead to a rather positive evaluation of CSR-related messages if the company has a lower overall CSR performance. Especially the CSR context is an important area in which distinctiveness, authenticity, and trustworthiness are highly relevant to inform and convince potential applicant and external stakeholders about the CSR activities of a company.

Second, the difference in the audiences on social media between high and low-CSR-performing companies may explain why low-CSR-performing companies tend to be more successful in receiving positive reactions for communicating CSR content. Potential applicants who particularly value CSR issues are likely to be attracted to companies that are already strong in CSR performance. In contrast, companies that perform somewhat low in CSR might initially attract potential applicants who might value other aspects of the future employer more strongly (e.g., career development opportunities). When presented with CSR content, potential applicants in the target audience of companies with a low CSR performance might react positively because they view CSR signals as adding onto other relevant organizational attributes. Potential applicants of companies with a high CSR performance, however, might be less receptive to additional CSR content, as they expected the company to regularly execute CSR activities. Similar results about the role of expectancies among stakeholders have been found for the reaction of the public, consumers, and employees to CSR communication (e.g., Korschun et al., 2016; Scheidler et al., 2019; White \& Willness, 2009). Future research might consider conducting experiments also among potential applicants to demonstrate how inconsistencies between CSR communication and CSR performance is attributed to expectancies as well as information processing differences in the perception of CSR signals.

Third, the lack of interaction effects can partly be due to the complex relationship between objective firm characteristics and subjective perceptions, also addressed in signaling theory as signal observability and receiver interpretation (Connelly et al., 2010). Even though we had operationalized CSR performance based on the CSRHub score, this characteristic may transfer in non-perfect and complex ways to the perception of observers. Although the overall negative main effects of a low CSR performance support the validity of the CSR score and the reasonableness of its scientific use, its role in the case of interactions with CSR content is more complex. In particular, evaluations of an organization vary depending on personal interests or values of observers, especially regarding topics such as environmental protection or human rights (Lange \& Washburn, 2012). These differences become relevant when judging either the relevance or appropriateness of the content communicated by the company. That is, observers may react positively to CSR content of companies with a low CSR performance either because they lack the information about CSR performance, or their values cause perceived information not to be salient in the moment of observing the post. As a future research implication, investigating the potential interaction effect with subjective perceptions of CSR performance would target the possibility of whether our results could be explained by a potential disparity of an objective versus perceived reputation.

\section{The Role of the Type of Inconsistency, Type of Receiver, and Context}

First, research on the effect of (in)consistency in CSR communication (e.g., Kim \& Choi, 2018; Scheidler et al., 2019; Skard \& Thorbjørnsen, 2014) and on the role of greenwashing or symbolic CSR (De Jong et al., 2018; Donia et al., 2019; Nyilasy et al., 2014) focuses on different types of inconsistencies. That is, studies vary according to the source of information where (in)consistent information is provided from. On the one hand, companies provide CSR information, but inconsistencies arise as the information on a same or similar issue (e.g., CSR) provides differing or even contradicting signals. For instance, there could be an imbalance between the extent companies pursue external versus internal CSR initiatives (Scheidler et al., 2019) or a (mis) 
fit between pre- versus post-crisis CSR initiatives (Kim \& Choi, 2018). In these cases, previous results indicate that inconsistencies are detrimental to stakeholder reactions (e.gKim \& Choi, 2018; Scheidler et al., 2019). On the other hand, inconsistencies may result from different information provided by different source, for instance, when the company communicates about its CSR initiatives in a different way than third parties do or objective data is showing (e.g., Nyilasy et al., 2014; Skard \& Thorbjørnsen, 2014). The study by Nyilasy et al. (2014), for instance, indicates that if a company exhibits high environmental performance, green advertising results in more unfavorable brand attitudes than no advertising. Our study provides indications in the same direction, since we found a dampening effect of CSR performance on the relationship between CSR communication and the (average) affective evaluation of CSR-related messages. Based on the arguments provided by Nyilasy et al. (2014), observers of CSR-related messages may start being skeptical about the "true" environmental/CSR performance when a company with high CSR performance strongly promotes its CSR performance for marketing purposes. Differences in the findings of the effect of inconsistencies provide a future research opportunity to further investigate how attributions about inconsistencies differ depending on the source and type of information (objective vs. subjective) that CSR communication is provided by.

Second, the type of receiver (e.g., potential applicants, employees, customers) could explain why the effect of inconsistency differs. Following signaling theory, the type of stakeholder reflects differences in the degree of information asymmetry that exist between sending entity (i.e., the company) and the receiver (i.e., stakeholder). Employees are likely to possess greater knowledge about their organization's CSR performance than do customers and potential applicants. At the same time, stakeholders' motivation to interact with the company is different so that the way corporate information is processed is different. While customers and potential applicants compare different companies as alternative opportunities to fulfill their need for a certain product or job, employees more strongly interact with one company they work for. The elaboration-likelihood model (Krosnick \& Petty, 1995; Petty \& Cacioppo, 1990) suggests that information is either processed via a central or a peripheral route depending, for instance, on the perceived personal consequence of a message. In the case of employees, CSR messages and corresponding inconsistencies might be processed via a central route which more likely results in the reconsideration of former attitudes. In contrast, potential applicants might resemble customers who tend to be confronted with different options in their product/job choice and, hence, might rather draw on superficial analyses of information. Some recent studies in consumer research back this argument as they indicate that inconsistencies might not always lead to negative reactions. For instance, De Jong et al. (2018) show that greenwashing companies create a better image if they communicate environmental issuers than if they would remain silent about environmental issues. Future research could consider exposing employees, consumers, and potential applicants to the same inconsistent CSR communication to compare the depth of information elaboration, attributions, and reactions.

Third, most of the studies that concern inconsistency or symbolic CSR use experiments to understand stakeholders' reactions (e.gDe Jong et al., 2018; Nyilasy et al., 2014; Skard \& Thorbjørnsen, 2014). Our study draws on data collected on real-life reactions to corporate Facebook career pages combined with CSR performance data. Thus, our study's analysis is based on objective data which adds a different perspective on the role of inconsistencies. On the one hand, our study shows higher external validity because the messages on which our study rests are crafted by companies and thus might depict a more natural type of communication than it is possible within an experiment. Additionally, observers' reactions in our study are more contextualized. Observers viewed messages embedded in all other Facebook communication and everyday communication that observers experience. Thus, the noisiness of the context might explain why our results might differ from experimental findings. Future research on stakeholders' reactions to inconsistencies could consider to introduce noise into experimental conditions to better understand how inconsistency and greenwashing affect consumers, employees, and potential applicants in our digital and information-overloaded society.

\section{Practical Implications}

Our study indicates that CSR communication can be beneficial in attracting applicants and that companies with a lower CSR performance might be successful in attracting candidates via social media. However, we would like to caution practitioners as both effects rely on the assumption of a linear trend underlying such extrapolations. It might be likely that linear extrapolations are only valid up to a certain point and that the potential relationship between the percentage of CSR content and reactions on a larger scale is non-linear or even U-shaped (Haans et al., 2016). That is, observers may become used to, bored, or even annoyed by CSR posts when offered in the extreme. This situation might already exist if the company has a superior CSR performance. Hence, we caution against regarding our results as a foundation for firms hoping to increase their social media performance by heavily focusing on CSR content. 


\section{Limitations and Outlook}

Although our study leverages unique data, the results must be interpreted considering limitations that present opportunities for future research. First, coding the posts on whether they had a CSR content or not was based on text mining to identify combination of terms that are indicative of CSR posts. While this procedure is objective, it results in an imperfectly accurate classification of posts. It can be expected that both false positives (i.e., posts misclassified as containing CSR content) and false negatives (i.e., failures to identify true CSR posts) exist. From a measurement theory viewpoint, these misclassifications represent random measurement error which downward biases the effect sizes. As our effect sizes were not only significant but also substantial, the download bias was apparently not so substantial that it led to the inability to find effects. On the contrary, it can be expected that because of the error, true effect sizes are even larger. As a future research implication, we suggest the application of modern forms of supervised text mining algorithms (Foster et al., 2016) not only to enhance a most accurate classification but also to estimate the amount of accuracy versus measurement error.

Second, conducting research with Facebook data involves some challenges, which is a potential area of future research on social media. These challenges are (A) the role of the algorithms on the visibility of different posts, (B) the non-independence of likes and shares, and (C) problems to infer causal effects. Regarding challenge (A), the Facebook algorithms cause prominent posts with a higher number of reactions to be promoted more among observers than posts with lower number of reactions. This differential visibility may potentially lead to selection bias (Elwert \& Winship, 2014), as the reactions to a post cause factual exclusion of unattractive posts out of the sample. Although such events are contained in the data, observers are less likely to be able to respond. It is possible, however, that the application of zero-inflation models, which we applied in this study, presents a remedy to this problem, as these models separate unobservable posts from the observable posts.

Concerning the non-independence of likes and shares in challenge (B), an additional problem may result from the number of likes and shares on the post level unlikely to be "iid" (independently and individually distributed) which is a basic assumption of statistical tests. In contrast, it is plausible that likes, and shares foster subsequent ones, thus particularly violating the independence assumption. Such non-independencies may stem either from the interrelatedness of individuals with similar standards or by individuals perceiving preceding likes as a signal pointing to the informational or emotional value of the post. Concerning the latter, a high number of likes can be regarded as a form of "descriptive norm" (Reno et al., 1993) signaling the social legitimization of a post. Again, investigating the correctness of these possibilities as well as the degree of non-independence and its consequences is a further research avenue to develop theory-enriching social media research.

Regarding problems to infer causal effects in challenge (C), causal inferences should be undertaken with care. In our study, we intended to enhance identifiability of the effects of CSR communication by controlling for most relevant potential confounders (VanderWeele, 2019). By controlling for industry and the $\mathrm{B} 2 \mathrm{C}$-segment, we eliminated the possibility that industry-related contents of posts interfere with industry-related differences in the attractiveness of posts. Furthermore, when controlling for CSR performance, we eliminated all confounding effects that are related to a fundamental attitude toward or against a company. As a potential future avenue of research, we suggest randomized controlled trials using scenarios to enhance causal interpretations of our results.

Third, the data underlying this study does not allow us to test for the potential explanations that would clarify why our results indicate that companies with a lower CSR performance seem to benefit more greatly from communicating their CSR activities on their Facebook career pages. We propose that CSR knowledge could play an important role in how potential applicants interpret CSR communication. However, the data does not provide us with a measure to directly test this explanation. Therefore, we suggest future research on CSR communication to include both inconsistency concerns and CSR knowledge to shed light on this potential interactive effect.

Fourth, the data underlying this study only includes organization-related characteristics. However, as proposed by the widely applied person-organization fit perspective, organizational attractiveness also depends on the fit between the characteristics of the applicant and the respective company (Cable \& Judge, 1994, 1996; Chatman, 1989). However, for privacy reasons, the data collection environment of this study did not allow us to control for individual level characteristics of the potential applicants. Nevertheless, we think that future research could greatly benefit from the inclusion of individual and organizational level characteristics in the investigation of the role of inconsistencies in CSR communication.

Acknowledgements We thank Jens Polomski for providing us with his excellent social media knowledge. We also thank the editor and two anonymous reviewers for their constructive and insightful feedback. 
Funding Open Access funding enabled and organized by Projekt DEAL.

\section{Declarations}

Conflict of interest The authors declare that they have no conflict of interest.

Open Access This article is licensed under a Creative Commons Attribution 4.0 International License, which permits use, sharing, adaptation, distribution and reproduction in any medium or format, as long as you give appropriate credit to the original author(s) and the source, provide a link to the Creative Commons licence, and indicate if changes were made. The images or other third party material in this article are included in the article's Creative Commons licence, unless indicated otherwise in a credit line to the material. If material is not included in the article's Creative Commons licence and your intended use is not permitted by statutory regulation or exceeds the permitted use, you will need to obtain permission directly from the copyright holder. To view a copy of this licence, visit http://creativecommons.org/licenses/by/4.0/.

\section{References}

Aguilera, R. V., Rupp, D. E., Williams, C. A., \& Ganapathi, J. (2007). Putting the $\mathrm{S}$ back in corporate social responsibility: A multilevel theory of social change in organizations. Academy of Management Review, 32(3), 836-863. https://doi.org/10.5465/amr.2007. 25275678

Aguinis, H., \& Glavas, A. (2012). What we know and don't know about corporate social responsibility: A review and research agenda. Journal of Management, 38(4), 932-968. https://doi.org/10.1177/ 0149206311436079

Albinger, H. S., \& Freeman, S. J. (2000). Corporate social performance and attractiveness as an employer to different job seeking populations. Journal of Business Ethics, 28(3), 243-253. https://doi.org/ 10.1023/A:1006289817941

Allen, D. G., Mahto, R. V., \& Otondo, R. F. (2007). Web-based recruitment: Effects of information, organizational brand, and attitudes toward a Web site on applicant attraction. Journal of Applied Psychology, 92(6), 1696. https://doi.org/10.1037/0021-9010. 92.6.1696

Alnıaçık, E., \& Alnıaçık, Ü. (2012). Identifying dimensions of attractiveness in employer branding: Effects of age, gender, and current employment status. Procedia-Social and Behavioral Sciences, 58, 1336-1343. https://doi.org/10.1016/j.sbspro.2012.09.1117

Arminen, H., Puumalainen, K., Pätäri, S., \& Fellnhofer, K. (2018). Corporate social performance: Inter-industry and international differences. Journal of Cleaner Production, 177, 426-437. https://doi.org/10.1016/j.jclepro.2017.12.250

Atkins, D. C., \& Gallop, R. J. (2007). Rethinking how family researchers model infrequent outcomes: A tutorial on count regression and zero-inflated models. Journal of Family Psychology, 21(4), 726-735. https://doi.org/10.1037/0893-3200.21.4.726

Azucar, D., Marengo, D., \& Settanni, M. (2018). Predicting the Big 5 personality traits from digital footprints on social media: A metaanalysis. Personality and Individual Differences, 124, 150-159. https://doi.org/10.1016/j.paid.2017.12.018

Backhaus, K. B., Stone, B. A., \& Heiner, K. (2002). Exploring the relationship between corporate social performance and employer attractiveness. Business \& Society, 41(3), 292-318. https://doi. org/10.1177/0007650302041003003
Barber, J., \& Thompson, S. (2004). Multiple regression of cost data: Use of generalised linear models. Journal of Health Services Research \& Policy, 9(4), 197-204. https://doi.org/10.1258/13558 19042250249

Barnett, M., Henriques, I., \& Husted, B. (2020). The rise and stall of stakeholder influence: How the digital age limits social control. Academy of Management Perspectives. https://doi.org/10.5465/ amp.2017.0080

Baum, M., \& Kabst, R. (2014). The Effectiveness of recruitment advertisements and recruitment websites: Indirect and interactive effects on applicant attraction. Human Resource Management, 53(3), 353-378. https://doi.org/10.1002/hrm.21571

Belinda, C. D., Westerman, J. W., \& Bergman, S. M. (2018). Recruiting with ethics in an online era: Integrating corporate social responsibility with social media to predict organizational attractiveness. Journal of Vocational Behavior, 109, 101-117. https://doi.org/ 10.1016/j.jvb.2018.10.001

Berk, R. A. (1990). A primer on robust regression. In J. L. Fox \& J. Scott (Eds.), Modern methods of data analysis. Newbury Park: Sage Publications.

Blevins, D. P., Tsang, E. W. K., \& Spain, S. M. (2015). Count-based research in management: Suggestions for improvement. Organizational Research Methods, 18(1), 47-69. https://doi.org/10. $1177 / 1094428114549601$

Cable, D. M., \& Judge, T. A. (1994). Pay preferences and job search decisions: A person-organization fit perspective. Personnel Psychology, 47(2), 317-348. https://doi.org/10.1111/j.17446570.1994.tb01727.x

Cable, D. M., \& Judge, T. A. (1996). Person-organization fit, job choice decisions, and organizational entry. Organizational Behavior and Human Decision Processes, 67(3), 294-311. https://doi.org/10.1006/obhd.1996.0081

Cable, D. M., \& Turban, D. B. (2001). Establishing the dimensions, sources, and value of job seekers'employer knowledge during recruitment. Research in Personnel and Human Resources Management, 20, 115-164.

Caers, R., \& Castelyns, V. (2010). LinkedIn and Facebook in Belgium: The influences and biases of social network sites in recruitment and selection procedures. Social Science Computer Review, 29(4), 437-448. https://doi.org/10.1177/0894439310 386567

Cameron, A. C., \& Trivedi, P. K. (2013). Regression analysis of count data (Vol. 53). Cambridge University Press.

Carlini, J., Grace, D., France, C., \& Lo Iacono, J. (2019). The corporate social responsibility (CSR) employer brand process: Integrative review and comprehensive model. Journal of Marketing Management, 35(1-2), 182-205. https://doi.org/10.1080/0267257X. 2019.1569549

Carpentier, M., Van Hoye, G., Stockman, S., Schollaert, E., Van Theemsche, B., \& Jacobs, G. (2017). Recruiting nurses through social media: Effects on employer brand and attractiveness. Journal of Advanced Nursing, 73(11), 2696-2708. https://doi.org/10. 1111/jan.13336

Carpentier, M., Van Hoye, G., \& Weijters, B. (2019). Attracting applicants through the organization's social media page: Signaling employer brand personality. Journal of Vocational Behavior, 115, 103326. https://doi.org/10.1016/j.jvb.2019.103326

Carroll, A. B. (1999). Corporates social responsibility: Evolution of a definitional construct. Business \& Society, 38(3), 268-295. https://doi.org/10.1177/000765039903800303

Celani, A., \& Singh, P. (2011). Signaling theory and applicant attraction outcomes. Personnel Review, 40(2), 222-238. https://doi. org/10.1108/00483481111106093

Chapman, D. S., Uggerslev, K. L., Carroll, S. A., Piasentin, K. A., \& Jones, D. A. (2005). Applicant attraction to organizations and job choice: A meta-analytic review of the correlates of recruiting 
outcomes. Journal of Applied Psychology, 90(5), 928-944. https://doi.org/10.1037/0021-9010.90.5.928

Chatman, J. A. (1989). Improving interactional organizational research: A model of person-organization fit. Academy of Management Review, 14(3), 333-349. https://doi.org/10.5465/amr.1989.42790 63

Chin, M. K., Hambrick, D. C., \& Treviño, L. K. (2013). Political ideologies of CEOs: The influence of executives' values on corporate social responsibility. Administrative Science Quarterly, 58(2), 197-232. https://doi.org/10.1177/0001839213486984

Connelly, B. L., Certo, S. T., Ireland, R. D., \& Reutzel, C. R. (2010). Signaling theory: A review and assessment. Journal of Management, 37(1), 39-67. https://doi.org/10.1177/0149206310388419

Conway, M., \& O'Connor, D. (2016). Social media, big data, and mental health: Current advances and ethical implications. Current Opinion in Psychology, 9, 77-82. https://doi.org/10.1016/j. copsyc.2016.01.004

Crane, A., \& Glozer, S. (2016). Researching corporate social responsibility communication: Themes, opportunities and challenges. Journal of Management Studies, 53(7), 1223-1252. https://doi. org/10.1111/joms.12196

Crocker, J., Fiske, S. T., \& Taylor, S. E. (1984). Schematic bases of belief change. In R. Eiser (Ed.), Attitudinal judgment (pp. 197226). Springer.

CSRHub (2019). https://www.csrhub.com. Accessed December 23, 2019.

CSRHub (2020). The CSRHub Ratings Methodology. https://esg. csrhub.com/csrhub-ratings-methodology. Accessed February 05, 2020.

De Jong, M. D. T., Harkink, K. M., \& Barth, S. (2018). Making green stuff? Effects of corporate greenwashing on consumers. Journal of Business and Technical Communication, 32(1), 77-112. https://doi.org/10.1177/1050651917729863

De Roeck, K., \& Maon, F. (2018). Building the theoretical puzzle of employees' reactions to corporate social responsibility: An integrative conceptual framework and research agenda. Journal of Business Ethics, 149(3), 609-625. https://doi.org/10.1007/ s10551-016-3081-2

De Roeck, K., El Akremi, A., \& Swaen, V. (2016). Consistency matters! How and when does corporate social responsibility affect employees' organizational identification? Journal of Management Studies, 53(7), 1141-1168. https://doi.org/10.1111/joms. 12216

Dhaoui, C., Webster, C. M., \& Tan, L. P. (2017). Social media sentiment analysis: Lexicon versus machine learning. Journal of Consumer Marketing, 34(6), 480-488. https://doi.org/10.1108/ JCM-03-2017-2141

Diez Roux, A. V. (2002). A glossary for multilevel analysis. Journal of Epidemiology and Community Health, 56(8), 588-594. https:// doi.org/10.1136/jech.56.8.588

Donia, M. B. L., Ronen, S., Tetrault Sirsly, C.-A., \& Bonaccio, S. (2019). CSR by any other name? The differential impact of substantive and symbolic CSR attributions on employee outcomes. Journal of Business Ethics, 157(2), 503-523. https://doi.org/10. 1007/s10551-017-3673-5

Du, S., Bhattacharya, C. B., \& Sen, S. (2010). Maximizing business returns to corporate social responsibility (CSR): The role of CSR communication. International Journal of Management Reviews, 12(1), 8-19. https://doi.org/10.1111/j.1468-2370.2009.00276.x

Eberle, D., Berens, G., \& Li, T. (2013). The impact of interactive corporate social responsibility communication on corporate reputation. Journal of Business Ethics, 118(4), 731-746. https://doi. org/10.1007/s10551-013-1957-y
Edwards, M. R. (2010). An integrative review of employer branding and OB theory. Personnel Review, 39(1), 5-23. https://doi.org/ 10.1108/00483481011012809

Ellen, S. P., Webb, D. J., \& Mohr, L. A. (2006). Building corporate associations: Consumer attributions for corporate socially responsible programs. Journal of the Academy of Marketing Science, 34(2), 147-157. https://doi.org/10.1177/0092070305 284976

Elwert, F., \& Winship, C. (2014). Endogenous selection bias: The problem of conditioning on a collider variable. Annual Review of Sociology, 40(1), 31-53. https://doi.org/10.1146/annur ev-soc-071913-043455

Employer Brand International (2014). Employer Branding Global Trends Study Report.

Etter, M., Colleoni, E., Illia, L., Meggiorin, K., \& D'Eugenio, A. (2016). Measuring organizational legitimacy in social media: Assessing citizens' judgments with sentiment analysis. Business \& Society, 57(1), 60-97. https://doi.org/10.1177/00076 50316683926

Etter, M., Ravasi, D., \& Colleoni, E. (2019). Social media and the formation of organizational reputation. Academy of Management Review, 44(1), 28-52. https://doi.org/10.5465/amr.2014.0280

Fischer, E., \& Reuber, R. (2007). The good, the bad, and the unfamiliar: The challenges of reputation formation facing new firms. Entrepreneurship Theory and Practice, 31(1), 53-75. https://doi.org/ 10.1111/j.1540-6520.2007.00163.x

Fiske, S. T., \& Taylor, S. E. (1991). Social Cognition. McGraw-Hill.

Floreddu, P. B., Cabiddu, F., \& Evaristo, R. (2014). Inside your social media ring: How to optimize online corporate reputation. Business Horizons, 57(6), 737-745. https://doi.org/10.1016/j.bushor. 2014.07.007

Fombrun, C., \& Shanley, M. (1990). What's in a name? Reputation building and corporate strategy. Academy of Management Journal, 33(2), 233-258. https://doi.org/10.5465/256324

Foster, I., Ghani, R., Jarmin, R. S., Kreuter, F., \& Lane, J. (2016). Big data and social science: A practical guide to methods and tools. Chapman and Hall/CRC.

Frasca, K. J., \& Edwards, M. R. (2017). Web-based corporate, social and video recruitment media: Effects of media richness and source credibility on organizational attraction. International Journal of Selection and Assessment, 25(2), 125-137. https:// doi.org/10.1111/ijsa.12165

Fraustino, J. D., \& Connolly-Ahern, C. (2015). Corporate associations written on the wall: Publics' responses to Fortune 500 ability and social responsibility Facebook posts. Journal of Public Relations Research, 27(5), 452-474. https://doi.org/10.1080/10627 26X.2015.1098543

Frostenson, M., Helin, S., \& Sandström, J. (2011). Organising corporate responsibility communication through filtration: A study of web communication patterns in Swedish retail. Journal of Business Ethics, 100(1), 31-43. https://doi.org/10.1007/ s10551-011-0771-7

Gao, H., Darroch, J., Mather, D., \& MacGregor, A. (2008). Signaling corporate strategy in IPO communication: A study of biotechnology IPOs on the NASDAQ. The Journal of Business Communication, 45(1), 3-30. https://doi.org/10.1177/0021943607309349

Gistri, G., Corciolani, M., \& Pace, S. (2019). Does the perception of incongruence hurt more? Customers' responses to CSR crises affecting the main reputation dimension of a company. Journal of Marketing Management, 35(7-8), 605-633. https://doi.org/10. 1080/0267257X.2019.1580761

Golovko, D., \& Schumann, J. H. (2019). Influence of company Facebook activities on recruitment success. Journal of Business Research, 104, 161-169. https://doi.org/10.1016/j.jbusres.2019. 06.029 
Gomes, D., \& Neves, J. (2011). Organizational attractiveness and prospective applicants' intentions to apply. Personnel Review, 40(6), 684-699. https://doi.org/10.1108/00483481111169634

Greening, D. W., \& Turban, D. B. (2000). Corporate social performance as a competitive advantage in attracting a quality workforce. Business \& Society, 39(3), 254-280. https://doi.org/10. 1177/000765030003900302

Haans, R. F. J., Pieters, C., \& He, Z.-L. (2016). Thinking about U: Theorizing and testing $\mathrm{U}$ - and inverted U-shaped relationships in strategy research. Strategic Management Journal, 37(7), 11771195. https://doi.org/10.1002/smj.2399

Hartmann, P., Fernández, P., Apaolaza, V., Eisend, M., \& D’Souza, C. (2020). Explaining viral CSR message propagation in social media: The role of normative influences. Journal of Business Ethics. https://doi.org/10.1007/s10551-020-04540-2

Hernandez, I., Newman, D. A., \& Jeon, G. (2015). Twitter analysis: Methods for data management and a word count dictionary to measure city-level job satisfaction. Big Data at Work (pp. 78-128). Routledge.

Highhouse, S., Thornbury, E. E., \& Little, I. S. (2007). Social-identity functions of attraction to organizations. Organizational Behavior and Human Decision Processes, 103(1), 134-146. https://doi. org/10.1016/j.obhdp.2006.01.001

Hox, J. J., Moerbeek, M., \& Van de Schoot, R. (2017). Multilevel analysis: Techniques and applications. Routledge.

Jones, D. A., Newman, A., Shao, R., \& Cooke, F. L. (2019). Advances in employee-focused micro-level research on corporate social responsibility: Situating new contributions within the current state of the literature. Journal of Business Ethics, 157(2), 293302. https://doi.org/10.1007/s10551-018-3792-7

Jones, D. A., Willness, C. R., \& Heller, K. W. (2016). Illuminating the signals job seekers receive from an employer's community involvement and environmental sustainability practices: Insights into why most job seekers are attracted, others are indifferent, and a few are repelled. Frontiers in Psychology. https://doi.org/ 10.3389/fpsyg.2016.00426

Jones, D. A., Willness, C. R., \& Madey, S. (2014). Why are job seekers attracted by corporate social performance? Experimental and field tests of three signal-based mechanisms. Academy of Management Journal, 57(2), 383-404. https://doi.org/10.5465/ amj.2011.0848

Jones, R., \& Murrell, A. J. (2001). Signaling positive corporate social performance: An event study of family-friendly firms. Business \& Society, 40(1), 59-78. https://doi.org/10.1177/0007650301 04000105

Joo, Y. R., Moon, H. K., \& Choi, B. K. (2016). A moderated mediation model of CSR and organizational attractiveness among job applicants: Roles of perceived overall justice and attributed motives. Management Decision, 54(6), 1269-1293. https://doi.org/10. 1108/MD-10-2015-0475

Kaplan, A. M., \& Haenlein, M. (2010). Users of the world, unite! The challenges and opportunities of Social Media. Business Horizons, 53(1), 59-68. https://doi.org/10.1016/j.bushor.2009.09.003

Kaur, P., Sharma, S., Kaur, J., \& Sharma, S. K. (2015). Using social media for employer branding and talent management: An experiential study. IUP Journal of Brand Management, 12(2), 7.

Kern, M. L., Park, G., Eichstaedt, J. C., Schwartz, H. A., Sap, M., Smith, L. K., et al. (2016). Gaining insights from social media language: Methodologies and challenges. Psychological Methods, 21(4), 507-525. https://doi.org/10.1037/met0000091

Kim, S. (2019). The process model of corporate social responsibility (CSR) communication: CSR communication and its relationship with consumers' CSR knowledge, trust, and corporate reputation perception. Journal of Business Ethics, 154(4), 1143-1159. https://doi.org/10.1007/s10551-017-3433-6
Kim, S., \& Choi, S. M. (2018). Congruence effects in post-crisis CSR communication: The mediating role of attribution of corporate motives. Journal of Business Ethics, 153(2), 447-463. https:// doi.org/10.1007/s10551-016-3425-y

Kim, S.-Y., \& Park, H. (2011). Corporate social responsibility as an organizational attractiveness for prospective public relations practitioners. Journal of Business Ethics, 103(4), 639-653. https://doi.org/10.1007/s10551-011-0886-X

Klein, K. J., \& Kozlowski, S. W. J. (2000). From micro to meso: Critical steps in conceptualizing and conducting multilevel research. Organizational Research Methods, 3(3), 211-236. https://doi. org/10.1177/109442810033001

Klimkiewicz, K., \& Oltra, V. (2017). Does CSR enhance employer attractiveness? The role of millennial job seekers' attitudes. Corporate Social Responsibility \& Environmental Management, 24(5), 449-463. https://doi.org/10.1002/csr.1419

Korschun, D., \& Du, S. (2013). How virtual corporate social responsibility dialogs generate value: A framework and propositions. Journal of Business Research, 66(9), 1494-1504. https://doi.org/ 10.1016/j.jbusres.2012.09.011

Korschun, D., Aggarwal, A., Rafieian, H., \& Swain, S. (2016). Taking a stand: Consumer responses to corporate political activism. Retrieved from SSRN website: https://ssrn.com/abstract, 2806476

Krosnick, J. A., \& Petty, R. E. (1995). Attitude strength: An overview. In Attitude strength: Antecedents and consequences (Vol. 1, pp. 1-24). London: Francis Group.

Landers, R. N., Brusso, R. C., Cavanaugh, K. J., \& Collmus, A. B. (2016). A primer on theory-driven web scraping: Automatic extraction of big data from the Internet for use in psychological research. Psychological Methods, 21(4), 475-492. https://doi. org/10.1037/met0000081

Lange, D., \& Washburn, N. T. (2012). Understanding attributions of corporate social irresponsibility. Academy of Management Review, 37(2), 300-326. https://doi.org/10.5465/amr.2010. 0522

Lee, S. Y., Zhang, W., \& Abitbol, A. (2019). What makes CSR communication lead to CSR participation? Testing the mediating effects of CSR associations, CSR credibility, and organization-public relationships. Journal of Business Ethics, 157(2), 413-429. https://doi.org/10.1007/s10551-017-3609-0

Lievens, F., \& Highhouse, S. (2003). The relation of instrumental and symbolic attributes to a company's attractiveness as an employer. Personnel Psychology, 56(1), 75-102. https://doi.org/10.1111/j. 1744-6570.2003.tb00144.x

Lin, L., Hung, P.-H., Chou, D.-W., \& Lai, C. W. (2019). Financial performance and corporate social responsibility: Empirical evidence from Taiwan. Asia Pacific Management Review, 24(1), 61-71. https://doi.org/10.1016/j.apmrv.2018.07.001

Lis, B. (2012). The relevance of corporate social responsibility for a sustainable human resource management: An analysis of organizational attractiveness as a determinant in employees' selection of a (potential) employer. Management Revue, 23(3), 279-295.

Lyon, T. P., \& Maxwell, J. W. (2011). Greenwash: Corporate environmental disclosure under threat of audit. Journal of Economics \& Management Strategy, 20(1), 3-41. https://doi.org/10.1111/j. 1530-9134.2010.00282.x

Lyon, T. P., \& Montgomery, A. W. (2013). Tweetjacked: The impact of social media on corporate greenwash. Journal of Business Ethics, 118(4), 747-757. https://doi.org/10.1007/s10551-013-1958-x

Miller, V. D., \& Jablin, F. M. (1991). Information seeking during organizational entry: Influences, tactics, and a model of the process. Academy of Management Review, 16(1), 92-120. https:// doi.org/10.5465/amr.1991.4278997

Morsing, M. (2006). Corporate social responsibility as strategic autocommunication: on the role of external stakeholders for member 
identification. Business Ethics: A European Review, 15(2), 171182. https://doi.org/10.1111/j.1467-8608.2006.00440.x

Newman, A., Nielsen, I., \& Miao, Q. (2015). The impact of employee perceptions of organizational corporate social responsibility practices on job performance and organizational citizenship behavior: Evidence from the Chinese private sector AU-Newman, Alexander. The International Journal of Human Resource Management, 26(9), 1226-1242. https://doi.org/10.1080/09585 192.2014.934892

Ng, V. K. Y., \& Cribbie, R. A. (2017). Using the gamma generalized linear model for modeling continuous, skewed and heteroscedastic outcomes in psychology. Current Psychology: A Journal for Diverse Perspectives on Diverse Psychological Issues, 36(2), 225-235. https://doi.org/10.1007/s12144-015-9404-0

Nikolaou, I. (2014). Social networking web sites in job search and employee recruitment. International Journal of Selection and Assessment, 22(2), 179-189. https://doi.org/10.1111/ijsa.12067

Nyilasy, G., Gangadharbatla, H., \& Paladino, A. (2014). Perceived greenwashing: The interactive effects of green advertising and corporate environmental performance on consumer reactions. Journal of Business Ethics, 125(4), 693-707. https://doi.org/10. 1007/s10551-013-1944-3

Pang, B., Lee, L., \& Vaithyanathan, S. (2002). Thumbs up? sentiment classification using machine learning techniques. Paper presented at the Proceedings of the ACL-02 conference on Empirical methods in natural language processing-Volume 10 ,

Pérez, A. (2019). Building a theoretical framework of message authenticity in CSR communication. Corporate Communications: An International Journal, 24(2), 334-350. https://doi.org/10.1108/ CCIJ-04-2018-0051

Petty, R. E., \& Cacioppo, J. T. (1990). Involvement and persuasion: Tradition versus integration. Psychological Bulletin, 107(3), 367-374. https://doi.org/10.1037/0033-2909.107.3.367

Reis, G. G., Braga, B. M., \& Trullen, J. (2017). Workplace authenticity as an attribute of employer attractiveness. Personnel Review, 46(8), 1962-1976. https://doi.org/10.1108/PR-07-2016-0156

Reno, R. R., Cialdini, R. B., \& Kallgren, C. A. (1993). The transsituational influence of social norms. Journal of Personality and Social Psychology, 64(1), 104-112. https://doi.org/10.1037/ 0022-3514.64.1.104

Rupp, D. E., Shao, R., Thornton, M. A., \& Skarlicki, D. P. (2013). Applicants' and employees' reactions to corporate social responsibility: The moderating effects of first-party justice perceptions and moral identity. Personnel Psychology, 66(4), 895-933. https://doi.org/10.1111/peps.12030

Rynes, S. L. (1991). Recruitement, job choice, and post-hire consequences: A call for new research directions. In M. D. Dunnette \& L. M. Hough (Eds.), Handbook of industrial and organizational psychology (2nd ed., Vol. 2, pp. 399-444). Palo Alto: Consulting Psychologists Press.

Saxton, G. D., Gomez, L., Ngoh, Z., Lin, Y.-P., \& Dietrich, S. (2019). Do CSR messages resonate? Examining public reactions to firms' CSR efforts on social media. Journal of Business Ethics, 155(2), 359-377. https://doi.org/10.1007/s10551-017-3464-Z

Scheidler, S., Edinger-Schons, L. M., Spanjol, J., \& Wieseke, J. (2019). Scrooge posing as Mother Teresa: How hypocritical social responsibility strategies hurt employees and firms. Journal of Business Ethics, 157(2), 339-358. https://doi.org/10.1007/ s10551-018-3788-3

Schreurs, B., Druart, C., Proost, K., \& De Witte, K. (2009). Symbolic attributes and organizational attractiveness: The moderating effects of applicant personality. International Journal of Selection and Assessment, 17(1), 35-46. https://doi.org/10.1111/j. 1468-2389.2009.00449.x
Schultz, F., Castelló, I., \& Morsing, M. (2013). The construction of corporate social responsibility in network societies: A communication view. Journal of Business Ethics, 115(4), 681-692. https:// doi.org/10.1007/s10551-013-1826-8

Sen, S., Bhattacharya, C. B., \& Korschun, D. (2006). The role of corporate social responsibility in strengthening multiple stakeholder relationships: A field experiment. Journal of the Academy of Marketing Science, 34(2), 158-166. https://doi.org/10.1177/ 0092070305284978

She, C., \& Michelon, G. (2019). Managing stakeholder perceptions: Organized hypocrisy in CSR disclosures on Facebook. Critical Perspectives on Accounting, 61, 54-76. https://doi.org/10.1016/j. cpa.2018.09.004

Sivertzen, A.-M., Nilsen Etty, R., \& Olafsen Anja, H. (2013). Employer branding: Employer attractiveness and the use of social media. Journal of Product \& Brand Management, 22(7), 473-483. https://doi.org/10.1108/JPBM-09-2013-0393

Skard, S., \& Thorbjørnsen, H. (2014). Is publicity always better than advertising? The role of brand reputation in communicating corporate social responsibility. Journal of Business Ethics, 124(1), 149-160. https://doi.org/10.1007/s10551-013-1863-3

Spence, M. (1978). Job market signaling. Uncertainty in Economics (pp. 281-306). Elsevier.

Swani, K., Brown, B. P., \& Milne, G. R. (2014). Should tweets differ for B2B and B2C? An analysis of Fortune 500 companies' Twitter communications. Industrial Marketing Management, 43(5), 873-881. https://doi.org/10.1016/j.indmarman.2014.04.012

Theurer, C. P., Tumasjan, A., Welpe, I. M., \& Lievens, F. (2018). Employer branding: A brand equity-based literature review and research agenda. International Journal of Management Reviews, 20(1), 155-179. https://doi.org/10.1111/ijmr.12121

Tonidandel, S., King, E. B., \& Cortina, J. M. (2018). Big data methods: Leveraging modern data analytic techniques to build organizational science. Organizational Research Methods, 21(3), 525547. https://doi.org/10.1177/1094428116677299

Tsai, Y.-H., Joe, S.-W., Lin, C.-P., \& Wang, R.-T. (2014). Modeling job pursuit intention: Moderating mechanisms of socio-environmental consciousness. Journal of Business Ethics, 125(2), 287-298. https://doi.org/10.1007/s10551-013-1919-4

Turban, D. B. (2001). Organizational attractiveness as an employer on college campuses: An examination of the applicant population. Journal of Vocational Behavior, 58(2), 293-312. https://doi.org/ 10.1006/jvbe.2000.1765

Turban, D. B., \& Greening, D. W. (1996). Corporate social performance and organizational attractiveness to prospective employees. Academy of Management Journal, 40(3), 658-672. https:// doi.org/10.5465/257057

Turban, D. B., \& Keon, T. L. (1993). Organizational attractiveness: An interactionist perspective. Journal of Applied Psychology, 78(2), 184-193. https://doi.org/10.1037/0021-9010.78.2.184

Tymon, W. G., Stumpf, S. A., \& Doh, J. P. (2010). Exploring talent management in India: The neglected role of intrinsic rewards. Journal of World Business, 45(2), 109-121. https://doi.org/10. 1016/j.jwb.2009.09.016

VanderWeele, T. J. (2019). Principles of confounder selection. European Journal of Epidemiology, 34(3), 211-219. https://doi.org/ 10.1007/s10654-019-00494-6

Verk, N., Golob, U., \& Podnar, K. (2019). A dynamic review of the emergence of corporate social responsibility communication. Journal of Business Ethics. https://doi.org/10.1007/ s10551-019-04232-6

Vishwanathan, P., van Oosterhout, H. J., Heugens, P. P. M. A. R., Duran, P., \& Van Essen, M. (2020). Strategic CSR: A concept building meta-analysis. Journal of Management Studies. https:// doi.org/10.1111/joms. 12514 
Wagner, T., Lutz, R. J., \& Weitz, B. A. (2009). Corporate hypocrisy: Overcoming the threat of inconsistent corporate social responsibility perceptions. Journal of Marketing, 73(6), 77-91. https:// doi.org/10.1509/jmkg.73.6.77

Walker, K., \& Wan, F. (2012). The harm of symbolic actions and green-washing: Corporate actions and communications on environmental performance and their financial implications. Journal of Business Ethics, 109(2), 227-242. https://doi.org/10.1007/ s10551-011-1122-4

Wang, Y., \& Berens, G. (2015). The impact of four types of corporate social performance on reputation and financial performance. Journal of Business Ethics, 131(2), 337-359. https://doi.org/10. 1007/s10551-014-2280-y

Wazed, S., \& Ng, E. S. W. (2015). College recruiting using social media: How to increase applicant reach and reduce recruiting costs. Strategic HR Review, 14(4), 135-141. https://doi.org/10. 1108/SHR-02-2015-0017

Wenzel, R., \& Van Quaquebeke, N. (2018). The double-edged sword of big data in organizational and management research: A review of opportunities and risks. Organizational Research Methods, 21(3), 548-591. https://doi.org/10.1177/1094428117718627

White, K., \& Willness, C. (2009). Consumer reactions to the decreased usage message: The role of elaborative processing. Journal of Consumer Psychology, 19(1), 73-87. https://doi.org/10.1016/j. jcps.2008.12.010

Willness, C. R. (2019). When CSR backfires: Understanding stakeholders' negative responses to corporate social responsibility. In D. E. McWilliams, D. E. Rupp, D. S. Siegel, G. Stahl, \& D. A. Waldman (Eds.), The Oxford handbook of corporate social responsibility: Psychological and organizational perspectives (pp. 1-2). Oxford University Press.
Wilson, R. E., Gosling, S. D., \& Graham, L. T. (2012). A review of facebook research in the social sciences. Perspectives on Psychological Science, 7(3), 203-220. https://doi.org/10.1177/17456 91612442904

Wood, D. J. (2016). Corporate social performance. https://www.oxfor dbibliographies.com/view/document/obo-9780199846740/obo9780199846740-0099.xml\#obo-9780199846740-0099-div20001. Accessed June 1, 2020.

Wu, Y., Zhang, K., \& Xie, J. (2020). Bad greenwashing, good greenwashing: Corporate social responsibility and information transparency. Management Science, 66(7), 3095-3112. https://doi.org/ $10.1287 / \mathrm{mnsc} .2019 .3340$

Zerfass, A., \& Schramm, D. M. (2014). Social Media Newsrooms in public relations: A conceptual framework and corporate practices in three countries. Public Relations Review, 40(1), 79-91. https:// doi.org/10.1016/j.pubrev.2013.12.003

Zhang, L., \& Gowan, M. A. (2012). Corporate social responsibility, applicants' individual traits, and organizational attraction: A person-organization fit perspective. Journal of Business and Psychology, 27(3), 345-362. https://doi.org/10.1007/ s10869-011-9250-5

Zhang, Q., Cao, M., Zhang, F., Liu, J., \& Li, X. (2020). Effects of corporate social responsibility on customer satisfaction and organizational attractiveness: A signaling perspective. Business Ethics: A European Review, 29(1), 20-34. https://doi.org/10. 1111/beer.12243

Publisher's Note Springer Nature remains neutral with regard to jurisdictional claims in published maps and institutional affiliations. 